\title{
UNA APROXIMACIÓN CONCEPTUAL DEL DAÑO Y SU IMPORTANCIA EN EL DIES A QUO DE LA PRESCRIPCIÓN DE LA ACCIÓN EN LA RESPONSABILIDAD EXTRACONTRACTUAL. UNA PROPUESTA NECESARIA RESPECTO DEL ARTÍCULO 2235 DEL CÓDIGO CIVIL ECUATORIANO
}

\author{
A CONCEPTUAL APPROACH BETWEEN \\ THE DAMAGE AND ITS IMPORTANCE \\ IN THE DIES A QUO OF THE STATUTE \\ OF LIMITATION IN THE TORTS DAMAGE ACTION. \\ A NECESSARY PROPOSAL REGARDING \\ OF ARTICLE 2235 OF THE ECUADORIAN CIVIL CODE
}

Leonardo Coronel Larrea*

RESUMEN

En el derecho ecuatoriano, el artículo 2235 del Código Civil ofrece una respuesta respecto a la contabilización de la prescripción de la acción en la responsabilidad extracontractual. No obstante, la regla genera una discusión cuando se habla de determinados casos que no están cobijados ni amparados por la interpretación clásica que da la norma. La solución fundacional com-

* Abogado magna cum laude por la Universidad San Francisco de Quito. Miembro de la Dirección Nacional de Asuntos Internacionales y Arbitraje de la Procuraduría General del Estado del Ecuador. Dirección Postal: 170703, Calles Camino al Conde y E2F, El Beaterio, Quito-Ecuador. Correo electrónico: leonardo.coronel@pge.gob.ec

Este trabajo de investigación fue presentado como trabajo de titulación, requisito para la obtención del título de abogado en el Colegio de Jurisprudencia de la Universidad San Francisco de Quito. En este sentido, es importante agradecer a Javier Jaramillo Troya por su gran guía y apoyo en la dirección y acompañamiento brindado durante la realización de este artículo, además de todos los consejos que me ha proporcionado con la finalidad de ayudar en mi crecimiento personal y profesional.

Igualmente, agradecer a Oswaldo Santos Dávalos por la oportunidad de disfrutar de la academia desde otra óptica, y a Vladimir Vilalba Paredes por enseñarme a amar la carrera y la profesión desde sus ejemplares clases. Finalmente, a todos mis profesores por trascender sus conocimientos en las siguientes generaciones.

Recepción: 2020-12-02; aceptación: 2021-06-07. 
prende que el cómputo de la prescripción tiene lugar desde la verificación del hecho ilícito, entendiendo que, en ese momento se ha perpetrado el acto. Sin embargo, esta postura no contempla la importancia de la existencia del elemento daño, ni de las formas en las que éste se manifiesta, en especial, el perjuicio oculto y continuado. Esto genera que exista un conflicto entre la regla general de que todo daño resarcible debe ser indemnizado y la seguridad en las relaciones jurídicas que busca la prescripción. En este sentido, es preciso delimitar el concepto de daño resarcible, además de entender y conocer cómo han sido concebidos los distintos tipos de menoscabos según su consumación en el tiempo desde la óptica jurídica ecuatoriana. Con esto se podrá analizar la prescripción y cómo han actuado la jurisprudencia y el derecho comparado en estos casos, donde se puede afirmar, que ya existe una solución que determine el inicio de la prescripción en casos de daño oculto y continuado. De esta forma, se propondrá una solución actual para el comienzo de la prescripción en el Ecuador.

PALABRAS ClaVE: responsabilidad civil; acción por daños; daño continuado; daño oculto; prescripción

In Ecuadorian Law, article 2235 of the Civil Code offers an answer regarding the accounting for the statute of limitations in the action for torts. However, the rule generates a discussion when certain cases are not covered or protected by the classical interpretation. The foundational interpretative rule understands that the calculation of the prescription must be from the verification of the wrongful act, understanding that the act has been perpetrated there. Nevertheless, this provision does not contemplate all types of damage, specifically hidden damage, and continued damage. This generates a conflict between the rule of the Torts Law that all damages must be compensated against the security in the legal relationships that the Statute of limitation seeks. Therefore, it is necessary to delimit the concept of compensable damage to understand and know how these types of damages have been conceived according to their consummation in time from an Ecuadorian conception. Accordingly, it will be possible to analyze the statute of limitation and how it has acted in case law and comparative law. In which, there is already a solution that determines the beginning of the statute of limitation in each case of hidden damage and continuing damage. In this way, a current solution will be proposed for the calculation of the statute of limitation in Ecuador.

KEYwORDs: torts law; damage action; continued damage; hidden damage; statutes of limitation 


\section{LA RESPUESTA APARENTEMENTE CLARA}

\section{Del artículo 2235 del Código Civil ecuatoriano:}

LA PRESCRIPCIÓN DE LA ACCIÓN POR DAÑOS EXTRACONTRACTUALES

El Código Civil ecuatoriano prescribe una solución que aparenta ser clara para el inicio de la contabilización del tiempo de la prescripción de la acción por daños extracontractuales. El artículo 2235 sostiene que: "[1]as acciones [...] por daño o dolo prescriben en cuatro años contados desde la perpetración del acto" ${ }^{1}$. No cabe duda de que la intención de Andrés Bello era proporcionar seguridad jurídica al determinar un dies a quo en la prescripción de la acción en la responsabilidad extracontractual. Asimismo, es indudable el grado de perfeccionamiento del código de Bello, pues como lo explica Claro Solar,

"por la belleza de su lenguaje, por la precisión y claridad de sus disposiciones, por la selección de los principios que convenían a nuestra sociabilidad en las diversas materias, por la armonía y correspondencia de sus partes, pocos Códigos modernos se le asemejan y podemos afirmar que ninguno le supera" ${ }^{3}$.

Sin perjuicio de esto, en palabras de Moisset de Espanés,

"[e]l campo de la responsabilidad civil tiene tal riqueza de contenido [...] que, pese a los numerosos estudios que se le dedican, continú[a] generando nuevas cuestiones, o exigiendo a la doctrina el esfuerzo de considerar aspectos que antes no había sido necesario analizar"4.

Un claro ejemplo es el dies a quo de la prescripción de la acción por daños extracontractuales en el ordenamiento jurídico ecuatoriano. La interpretación fundacional o clásica que se le ha dado a este artículo concibe que la prescripción correrá desde la verificación del hecho ilícito en todos los casos, sin distinciones, ya que se ha entendido que en ese momento se ha perpetrado el acto $^{5}$. En este sentido, a pesar de que, en la actualidad, la interpretación que se le da a la norma aún puede surtir efectos, deja por fuera supuestos en los que la manifestación de la afectación ocurre de diferente forma. En un daño instantáneo o consumado tras el hecho que lo causó, no habría problema, ya que la prescripción iniciaría desde el cometimiento del hecho porque en ese momento se verificarían todos los elementos necesarios de la responsabilidad civil extracontractual. No obstante, existen casos en los que

${ }^{1}$ Artículo 2235. Código Civil, de 2019.

${ }^{2}$ Diccionario del español jurídico de la Real Academia de la Lengua Española (2020), "dies a quo" (explicando el término latino que significa "día inicial del cómputo de").

${ }^{3}$ Claro Solar (1978), p. 21.

${ }^{4}$ Moisset de Espanés (1990), p. 1.

${ }^{5}$ Alessandri (2015); Ferrada (2012); Tapia (2016); y, Vergara (2004) o Vergara (2011). 
no se puede apreciar de manera inmediata después del hecho generador todos estos elementos, lo que provoca que la víctima no conozca que sufrió un daño o que lo siga sufriendo.

En estos escenarios, la aplicación de la misma regla devendría en una vulneración del derecho de la víctima a ser indemnizada a causa de la institución de la prescripción, debido a la forma en la que estos menoscabos se manifiestan. Esta situación genera una violación al principio general de indemnización frente a todo daño ${ }^{6}$, que encuentra asidero en el artículo 2214 del Código Civil, que manda que "[e]l que ha cometido un delito o cuasidelito que ha inferido daño a otro, está obligado a la indemnización [...]”", o el artículo 2229 del mismo cuerpo normativo que prescribe que "[p]or regla general todo daño que pueda imputarse a malicia o negligencia de otra persona debe ser reparado por ésta"8. En síntesis, la víctima se encontraría sin protección; efecto totalmente contrario al propósito del derecho de daños.

Este es el caso, por ejemplo, de un procedimiento quirúrgico en el que uno de los doctores olvida una gasa dentro de su paciente y la manifestación de la afectación ocurre seis años después. La aplicación de la regla, según la interpretación fundacional, haría que la acción se encuentre prescrita a partir del cuarto año sin importar en qué momento se manifieste el perjuicio. La misma situación ocurre, con una afectación que se prolonga durante cinco años, si se contabiliza la prescripción desde el inicio del menoscabo, a partir 234 del cuarto año la acción por daños estaría prescrita. Este criterio no toma en cuenta si existía la posibilidad de demandar o la forma en la que el menoscabo se estaba manifestando. Con esto en mente, se puede afirmar que computar la prescripción desde el cometimiento del hecho ilícito no es la solución correcta en ninguno de estos casos, por lo que es necesario buscar una respuesta que evite una aplicación ciega de la norma y fuera de los objetivos de la prescripción.

Para cumplir esta meta, es preciso establecer y aclarar ciertas confusiones que se presentan en el derecho ecuatoriano, por lo que es esencial cimentar las bases de la responsabilidad civil extracontractual, en particular, lo referente al elemento del daño y sus distintas tipologías de consumación en el tiempo, que no han sido desarrolladas o su concepción ha sido nula en este régimen jurídico. Incluso, analizar esto ayudará a entender su presencia necesaria, ya que la interpretación fundacional olvida que la existencia de este elemento es fundamental para poder hablar de una acción de responsabilidad civil. Entonces, la idea es definir, mediante una aproximación conceptual, por qué la existencia del daño es un pilar fundamental dentro de la responsabilidad civil, así como conocer cuándo este es resarcible. Esto permitirá demostrar que la manifestación de la afectación, en cualquier caso, es necesaria y de esta dependerá la forma en la que se aplique la regla del artículo 2235 del

\footnotetext{
${ }^{6}$ Abeliuk (2008), pp. 169-171.

${ }^{7}$ Artículo 2214. Código Civil, de 2019.

${ }^{8}$ Artículo 2229. Código Civil, de 2019.
} 
Código Civil respecto de la prescripción. Hay que tener presente que, "[1] as normas de los códigos son pulmones que le permiten al código respirar, abrirse, adecuarse a la realidad que trata de regular"

Entonces, queda claro que en el sistema jurídico ecuatoriano no existe una solución establecida para el cómputo efectivo de la prescripción en la acción dentro de la responsabilidad extracontractual, por lo que, a través de la doctrina, la jurisprudencia y el derecho comparado se buscará esclarecer esta problemática. Con este objetivo, este trabajo se encargará de analizar la importancia del daño como un presupuesto de responsabilidad civil [infra II]. Esto llevará a verificar las distintas clases de afectaciones según su consumación en el tiempo [infra III]. Y finalmente, hablar de la prescripción y su íntima relación con las distintas tipologías de daño [infra IV].

\section{EL DAÑO COMO PRESUPUESTO}

DE RESPONSABILIDAD CIVIL EXTRACONTRACTUAL

Se ha establecido como idea fundamental que existen cuatro elementos materiales para que pueda existir responsabilidad civil ${ }^{10}$. Al respecto, la Corte Suprema de Justicia ecuatoriana determinó que se requiere:

“a) [Q]ue el hecho o acto sea contrario a las normas legales o reglamentarias; b) [Q]ue haya dolo, culpa u otro factor determinado por la ley; c) [Q]ue exista daño patrimonial o moral; y, d) [Q]ue medie un nexo de causalidad entre el hecho o acto ilícito y el daño"11.

Esta sección se enfocará en el elemento del daño y su importancia dentro de la responsabilidad civil, toda vez que el análisis conduce a una delimitación de las clases de perjuicios y la forma de correlacionarse con la prescripción [infra IV]. Por lo tanto, se realizará una descripción de este elemento como una condición y el objeto de reparación del derecho de daños [1]. Asimismo, se delimitará su definición como elemento de responsabilidad civil [2]. Y, se detallarán los elementos necesarios para que este pueda configurarse [3].

\section{El Daño como condición inexorable y objeto de reparación en la responsabilidad civil}

La consciencia básica de "la obligación de reparar el daño causado en la persona o bienes de otro es tan antigua como el hombre mismo"12. Sin embargo,

\footnotetext{
${ }^{9}$ Busnelli (1984), p. 50 (traducción no oficial).

${ }^{10}$ Corral (2003), pp. 105-217.

${ }^{11}$ V. con Colegio de Médicos de Imbabura (2003).

${ }^{12}$ Velásquez Posada (2016), p. 189.
} 
esta idea ha ido cambiando según la época en que se le analiza. El punto de partida que se conoce es la etapa de la venganza regulada, reflejada en el Código de Hammurabi y su ley del Talión ${ }^{13}$. Como dice Ihering,

"la injusticia es apreciada no según su causa, sino según su efecto; no según las circunstancias relativas a la persona del actor, sino desde el ángulo de la víctima. La piedra lo ha golpeado, él siente dolor, y el dolor lo empuja a la venganza" ${ }^{14}$.

Con el pasar del tiempo, este concepto fue reemplazado por un sistema reglado de reparación; no obstante, la esencia sigue intacta. El principal objetivo es buscar cómo solventar la afección causada, con lo cual se demuestra su relevancia en la responsabilidad civil.

Por esta razón, cabe destacar a este elemento como un presupuesto indispensable en la responsabilidad aquiliana. Como sostiene Alessandri, no basta la acción u omisión ilícita con culpa o dolo, sino que es necesario el resultado dañoso ${ }^{15}$. El resarcimiento solicitado sería denegado al no verificarse este presupuesto material. Se puede afirmar que el daño es el fundamento, así como el prius de la responsabilidad civil extracontractual ${ }^{16}$. Por lo tanto, metafóricamente, se dice que en la génesis de la responsabilidad civil está el daño ${ }^{17}$.

Por ejemplo, si una persona que se encuentra en estado de ebriedad condu236 ce su vehículo en contra vía al tránsito permitido, no existirá responsabilidad civil hasta que se verifique la existencia de un detrimento, sea reflejado en un choque automovilístico, la afectación de la propiedad privada, las lesiones de los pasajeros o las afectaciones a un bien de uso público. Esta ilustración, no sólo permite aclarar que, a pesar de existir una acción ilícita culposa, no existe responsabilidad civil si no existe un daño. También, permite dejar claro que la responsabilidad penal es distinta a la responsabilidad civil ${ }^{18}$, puesto que si bien este hecho está sujeto al juicio de valor en el ámbito penal y las leyes de tránsito que se hayan vulnerado, es claro que la pena que se imponga no será por el ilícito culposo civil, sino por la tipificación correspondiente del Código Orgánico Integral Penal ${ }^{19}$. Criterio similar manifestó la Corte Suprema de Justicia ecuatoriana en C. con Constructora $\mathrm{S}^{20}$ cuando afirmó que la responsabilidad derivada de un delito o cuasidelito genera una acción que es "autónoma, independiente de otra acción [...] penal".

${ }^{13}$ Velásquez Posada (2016), p. 189.

${ }^{14}$ Von Ihering (1880), p. 10 (traducción no oficial).

${ }^{15}$ Alessandri (2015), pp. 151-153.

${ }^{16}$ De Lorenzo (1996), p. 12.

${ }^{17}$ Barros (2006), pp. 215-216.

${ }^{18}$ Coronel \& Chiriboga (2019), pp. 36-40, explicando la confusión entre la responsabilidad penal y civil en el antiguo derecho ecuatoriano por el derogado artículo 41 del Código de Procedimiento Penal.

${ }^{19}$ Artículos 385 y 390 numeral 3. Código Orgánico Integral Penal, de 2019.

${ }^{20}$ C. con Constructora S. (1983). 
El principal objetivo del derecho de daños es la función indemnizatoria que trae consigo, que siempre estará encaminada a buscar que todos los perjuicios sean reparados ${ }^{21}$. Esto va de la mano con lo que Barros determina como "el objeto del juicio de responsabilidad" 22 . En estricto sentido, la finalidad es la reparación del daño sufrido que se busca conseguir en el juicio de responsabilidad civil.

En definitiva, queda claro que, la existencia de las afectaciones es connatural al ser humano, por ende, siempre se ha buscado la forma de repararlos. Asimismo, se conoce que el daño es una condición inexorable para la existencia de responsabilidad civil, además de ser su reparación o compensación, según sea el caso, la pretensión dentro del juicio de responsabilidad extracontractual. En esencia, este elemento es el inicio y fin del derecho de daños.

\section{La definición jurídica de daño}

Durante los últimos años, la concepción del término daño ha ido evolucionando. En un principio, existía la distinción entre este y el perjuicio donde el primero era una referencia directa a la consecuencia de las cosas por un hecho ilícito, mientras que el segundo estaba enfocado a aquella afectación que sufría la persona por el detrimento de la cosa. Esta diferenciación era una aplicación evidente de la Lex Aquilia ${ }^{23}$. De la misma manera, existen otras concepciones que entienden al mismo término como un sinónimo de daño emergente, mientras que el perjuicio sería una referencia al lucro cesante; ambos, tipos de perjuicio patrimonial ${ }^{24}$. En la actualidad no existe una distinción, ya que se los puede considerar como sinónimos. Inclusive, el Código Civil en varios artículos utiliza los términos indistintamente ${ }^{25}$.

Si se afirma que la existencia del daño, perjuicio o afectación es connatural al ser humano, es menester determinar cuándo este puede ser resarcible. Para ello, se recurre al uso del derecho. La jurisprudencia ecuatoriana ha sido enfática en afirmar que "el daño fáctico es distinto al daño jurídico" ${ }^{26}$. Entonces, será indemnizable todo daño jurídico, es decir aquel que le importa al ordenamiento ${ }^{27}$. Sin perjuicio de esto, han existido varias posturas que explican cuándo se habla de un perjuicio juridizado. Por ejemplo, hay quienes sostienen que éste tiene que recaer sobre un derecho real o personal para que sea resarcible (concepción restrictiva) ${ }^{28}$.

${ }^{21}$ Diez-Picazo (2005), p. 28.

${ }^{22}$ Barros (2006), p. 216.

${ }^{23}$ Mazeaud et al. (1961), pp. 292-295.

${ }^{24}$ Comité D. T. viuda de C. con Petroecuador (2002).

${ }^{25}$ Artículos 145, 1502 y 1950. Código Civil, de 2019, explicando la utilización de los términos daño y perjuicio como sinónimos.

${ }^{26}$ Comité D. T. viuda de C. con Petroecuador (2002).

${ }^{27}$ CORRal (2003), pp. 137-138.

${ }^{28}$ TAmaYo (2007), pp. 310-315. 
Por el contrario, existe una tesis que fundamenta que el menoscabo debe recaer sólo sobre un interés que la persona percibía o iba a percibir, siendo este suficiente para que pueda entenderse como una afectación jurídica ${ }^{29}$. Según de Cupis, el concepto de interés deriva del concepto de bien, siendo todo lo que pueda satisfacer una necesidad humana ${ }^{30}$. Actualmente, se puede afirmar que la concepción de daño genera un espectro sumamente amplio ${ }^{31}$. De esta manera,

"daño no es ya, en la conciencia social, ni en la praxis jurisprudencial, ni en las propias intervenciones legislativas, un simple detrimento del patrimonio de la víctima del ilícito: daño es la lesión de un interés protegido y se agota en esto" 32 .

Es decir, que exista una desmejora en una situación que la víctima tenía previo a la afectación.

La RAE define al daño como aquel "detrimento, perjuicio, menoscabo, dolor o molestia" ${ }^{33}$. De forma mayoritaria, la doctrina ha acogido esta concepción para explicar en qué consiste el elemento del daño. No obstante, el principal punto de debate es el ámbito en el que puede existir un detrimento o menoscabo. Con anterioridad, se explicó que la concepción actual del daño se sujeta a una definición amplia, por lo que no sólo se habla de afectación al patrimonio de las personas, sino una esfera más allá que carece de una determinación pecuniaria $^{34}$. En este sentido, Henao afirma que "[e]l daño es un hecho: es toda forma de afrenta a la integridad de una cosa, una persona, de una actividad, o de una situación" ${ }^{35}$. Esta definición estaría acorde al Código Civil ecuatoriano, toda vez que en su articulado admite la indemnización por daños extrapatrimoniales ${ }^{36}$. Por lo tanto, se puede acoger la definición de Tamayo, cuando sostiene que "el daño es todo menoscabo que sufre una persona a un derecho subjetivo o aptitud de disfrute a un bien que puede ser patrimonial o extrapatrimonial" ${ }^{37}$.

Una vez establecida una definición jurídica del elemento, hay que precisar sus límites. Esto implica diferenciar aquellas turbaciones que pueden ser soportadas por las personas por el hecho de vivir en sociedad, frente a los daños jurídicos que serán susceptibles de reparación ${ }^{38}$. Es decir, conocer cuándo se puede endosar un infortunio a otra persona distinta a quien lo recibió. Se trata de una cuestión importante de aclarar, ya que el desarrollo jurisprudencial ecuatoriano no considera la importancia de identificar y co-

${ }^{29}$ Alessandri (2015), pp. 153-156.

${ }^{30}$ De Cupis (1975), p. 111.

${ }^{31}$ Escudero (2019), pp. 4-7.

${ }^{32}$ AlPa (2006), p. 773.

${ }^{33}$ Diccionario de la Real Academia Española (2020), “daño".

${ }^{34}$ Weingarten (2005), p. 157.

${ }^{35}$ Henao (1998), p. 76.

${ }^{36}$ Artículo 2232. Código Civil de 2019.

${ }^{37}$ TAMAYO (2007), pp. 326-334.

${ }^{38}$ Barros (2006), pp. 219-222. 
rroborar la existencia de un daño que le interesa al ordenamiento para que sea resarcible. En este sentido, daño jurídico indemnizable será aquel que cumpla con los elementos que se desarrollarán a continuación.

\section{Elementos del daño resarcible}

Cuando el daño jurídico entra en juego, lo más importante es la característica de ser indemnizable ${ }^{39}$. Para Bustamante Alsina deben converger cuatro elementos para que el daño pueda ser resarcible, estos son que: "[el] daño debe ser cierto, subsistente, personal del reclamante y afectar a un interés legítimo del damnificado" ${ }^{40}$. En realidad, la característica de daño personal del reclamante no se puede considerar como un requisito ontológico de este elemento. Esta discusión sería un problema procesal de legitimación en la causa $^{41}$, o de legitimación en el proceso. De esta manera, se necesita el cumplimiento de tres únicos elementos.

El primer requisito es la certidumbre. En palabras de Alessandri "el daño debe ser cierto, es decir, real, efectivo, tanto que, a no mediar él, la víctima se habría hallado en mejor situación" ${ }^{42}$. Se puede afirmar que considerar algo como verdadero o real implicará, indudablemente, su certidumbre, y es trabajo del juez llegar a esa conclusión ${ }^{43}$. Esto implica que el daño haya sucedido o sea probable que ocurra, evitando así caer en un supuesto hipotético ${ }^{44}$. Al respecto, la Corte Suprema de Justicia de Colombia ha manifiestado que:

“[1]a premisa básica consiste en la reparación del daño causado, solo el daño y nada más que el daño, con tal que sea cierto en su existencia ontológica" ${ }^{45}$,

precepto que además de confirmar el requisito, establece que la obligación de resarcir e indemnizar será solo en el valor dañado para evitar el enriquecimiento sin causa.

El segundo requisito es que el menoscabo afecte a un interés legítimo o lícito de la víctima. Este elemento tiene una relación estrecha con la evolución de los bienes jurídicamente tutelados explicados con anterioridad [supra 2]. En estricto sentido, el daño ya no protegería únicamente a los derechos reales y personales de las personas, sino a intereses de manera general. Una vez determinado el campo en el que debe existir la afectación, es preciso determinar su legitimidad o licitud. Tamayo sostiene que se hablará de afectación

\footnotetext{
39 Velásquez Posada (2016), pp. 269-271.

${ }^{40}$ Bustamante Alsina (1998), p. 170.

${ }^{41}$ Velásquez Posada (2016), pp. 273-275.

42 Alessandri (2015), p. 156.

43 Velásquez Posada (2016), pp. 270-273.

${ }^{44}$ ZANNONI (2005), pp. 233-236.

${ }^{45}$ Caso n. ${ }^{\circ}$ 17042-3103-001-2005-00103-01 (2010).
} 
legítima o lícita a cualquier menoscabo que sufra una persona en contra de un interés o bien tutelado que no se encuentre prohibido por la ley ${ }^{46}$. En conclusión, este elemento se verificará cuando exista una afectación a un derecho o interés de la víctima que esté amparado en el ordenamiento, y que no esté prohibido por la ley.

El tercer requisito es la subsistencia del daño. Este elemento busca que la afectación se mantenga al momento de su reclamo, que no haya sido indemnizado con anterioridad ${ }^{47}$. $\mathrm{Al}$ respecto, los Mazeaud afirman que es "una perogrullada" ${ }^{48}$, toda vez que si ha sido resarcido, la obligación se ha cumplido y por ende se encuentra extinguida. No obstante, pueden existir hipótesis en las que esta exigencia deba verificarse. Por ejemplo, en el caso en el que el daño haya ocurrido efectivamente, pero al momento del reclamo el hecho haya parado, la subsistencia se manifestará por la falta de reparación ${ }^{49}$. Asimismo, se puede hablar de un daño resarcido de forma aparente, es decir, no reparado en su totalidad; situación que expondrá la subsistencia de dicho menoscabo y cumplimiento de este requisito.

Se desprende de esta sección que el elemento material del daño es de suma importancia dentro de la responsabilidad civil, al ser una condición inexorable y su reparación el objeto pretendido en la responsabilidad aquiliana [supra II.1]. También, se ha llegado a la conclusión que el daño jurídico es aquel que el ordenamiento propende su reparación y se lo puede definir como toda 240 afectación, menoscabo o detrimento que puede sufrir la persona tanto en sus bienes como en su persona, siempre y cuando se hable de intereses o bienes tutelados por el ordenamiento [supra II.2]. Finalmente, se estableció que los límites a esta definición amplia de daño son los requisitos que ha establecido la doctrina en tres categorías, y es:

1) que sea cierto;

2) que la afectación recaiga en un interés legítimo o lícito; y,

3) que el daño sea subsistente al momento de su reclamación [supra II.3]. Dicho esto, a continuación es importante ahondar en las posibles formas en las que los menoscabos se manifiestan en el tiempo, categorías que influirán en el análisis del artículo 2235 del Código Civil.

\section{LA CLASIFICACIÓN DEL DAÑO SEGÚN SU CONSUMACIÓN EN EL TIEMPO}

En el derecho ecuatoriano esta clasificación no ha sido profundizada. Esto conlleva el uso de fuentes externas para delimitar y establecer ciertas diferen-

\footnotetext{
${ }^{46}$ TAMayo (2007), pp. 326-334

${ }^{47}$ ZANNONi (2005), pp. 43-46.

${ }^{48}$ Mazeaud et al. (1961), p. 385.

${ }^{49}$ Bustamante Alsina (1998), pp. 169-174.
} 
cias que resultan importantes para el objeto de este trabajo. El análisis de esta categoría siempre va dirigida a responder temas del quantum indemnizatorio o el a dies a quo de la prescripción ${ }^{50}$. Por lo tanto, se establecerán los diferentes tipos de daño según su tiempo de consumación o duración en el tiempo ${ }^{51}$.

Esta clasificación muestra que las afectaciones pueden presentarse de distintas formas. En primer lugar, se explicará la categoría simple y sin inconvenientes. Es decir el consumado o instantáneo, donde se buscará aclarar la categoría de daño permanente, siendo una subcategoría de este. Es importante desmitificar la categoría de ese perjuicio, ya que puede causar confusión cuando se la asimila a un daño continuado, conclusión incorrecta e inaceptable [1]. Asimismo, se analizará el daño continuado o sucesivo, donde se especificará que es aquel que su hecho generador y su efecto se prolonga en el tiempo [2]; de la misma manera se explicará la clasificación del daño oculto, tardío o sobrevenido [3]; y, para finalizar, se estudiará el daño contingente y sus características [4].

\section{El daño consumado o instantáneo. La desmitificación del perjuicio permanente}

La afectación que se manifiesta en su totalidad tras el hecho que lo causó es denominado consumado o instantáneo. Éste se "materializa instantáneamente, y su dimensión queda fijada definitivamente" ${ }^{52}$. Por ejemplo, cuando se habla de un choque automovilístico en el que se destruye un objeto no fructífero, el menoscabo sufrido puede determinarse con bastante precisión. Sin duda, es la hipótesis que no presenta dificultades al momento de contabilizar el tiempo de prescripción, ya que todos los elementos necesarios para que exista responsabilidad civil convergen en un mismo momento fáctico y jurídico.

Dentro de esta misma categoría existe el perjuicio duradero o permanente. Este tipo de menoscabo "se define como el provocado por un acto aislado, que extiende sus efectos en el tiempo" ${ }^{53}$. En esta categoría, la característica fundamental que se puede observar es la prolongación de la afectación o menoscabo hacia el futuro. Esto llevaría a inferir que un perjuicio que se prolongue en el tiempo tiene la denominación de continuado, aunque esto no es así. Para Moisset de Espanés, existen dos tipos de daños sucesivos, aquellos que involucran hechos generadores continuados e instantáneos ${ }^{54}$. Sin embargo, se discrepa de esta concepción, ya que es preciso distinguir entre los daños permanentes o duraderos y aquellos a los que se denomina como daños efectivamente continuados que se analizarán más adelante ${ }^{55}$. No

\footnotetext{
${ }^{50}$ ARMAdÀ (2015), p. 29.

${ }^{51}$ Roca y Navarro (2016), p. 207.

${ }^{52}$ Moisset de Espanés (1990), pp. 1-5.

${ }^{53}$ Cavanillas (2013), p. 13323.

${ }^{54}$ Moisset de Espanés (1990), pp. 5-10.

${ }^{55}$ Causa n. ${ }^{\circ}$ 1580/2014 (2016).
} 
obstante, su diferencia estructural puede evidenciarse después de un análisis del hecho generador y el efecto.

Como se observa, en una afectación permanente o duradera el hecho se produce en un momento determinado, y el efecto dañoso, que se consuma al instante, es el que persiste a lo largo del tiempo. Por lo tanto, el acto generador y el daño se agota en un momento concreto, aun cuando sea inalterable y permanente en el tiempo el resultado lesivo.

Como se explicó, la figura del menoscabo instantáneo o consumado es la figura que no presenta mayor problemática en el análisis de la responsabilidad, y en el caso de los perjuicios permanentes el criterio es el mismo. Por ello, se sostiene que el daño duradero o permanente es una forma en la que el consumado se puede expresar.

Por ejemplo, cuando una persona, como consecuencia de un hecho antijurídico, queda parapléjica o pierde una extremidad se deduce que es un daño instantáneo permanente. El hecho generador se produjo en un momento determinado, sin perjuicio que la afectación se prolongue de forma indefinida en el tiempo. Esta precisión ha sido acogida por el Tribunal Supremo de España, que incluso afirma que, existe "la posibilidad, [...] de agravarse [los daños] por factores ya ajenos a la acción u omisión del demandado" 56 .

Una vez explicada la categoría de daño consumado y permanente como una subcategoría de esta tipología, es preciso ahondar en los tipos que pre242 sentan mayor problemática el momento de aplicar la regla del artículo 2235 del Código Civil.

\section{El daño continuado o de producción sucesiva}

El daño efectivamente continuado o de producción sucesiva es la afectación que se caracteriza por la presencia de un hecho generador que se prolonga en el tiempo, calificándose como continuado gracias al modo en que se generan las afectaciones ${ }^{57}$. La sala segunda de la Cámara de Apelaciones en lo civil y comercial de Mar de la Plata, en T. y otros con S., sostuvo que:

"[e]l daño es continuado cuando la causa generadora y removible actúa en forma constante, sin interrupciones, renovando permanentemente el perjuicio a los intereses de la víctima" ${ }^{58}$.

Si se toma en cuenta el mismo análisis de hecho generador y efecto dañoso, se entiende por qué puede ser catalogado como continuado, debido a que

${ }^{56}$ Causa n. $^{\circ}$ 28/2014 (2014).

${ }^{57}$ Marín López (2014), pp. 5-7.

${ }^{58}$ Tomietto y otros con Salvador (2019). 
"[s]on aquellos en los que la causa que origina el daño se mantiene ininterrumpidamente [hecho generador]; y por lo tanto sigue generando daños [efecto dañoso]" 59 .

En otras palabras, son aquellos que renuevan su causa de manera continua. Para Reglero, la inexistencia de paralización en la causa es de suma importancia, dado que

“es necesario que el perjudicado los esté efectivamente sufriendo, pues no puede considerarse que hay actividad dañosa continuada cuando aun prolongándose en el tiempo, el que resultaba perjudicado por ella dejó de serlo en un momento determinado" 60 .

A criterio propio, lo esencial de un daño continuado es la posibilidad que existe de que la manifestación del mismo se suspenda o sea removible. Es decir, la existencia de un criterio de reversibilidad del hecho tras la suspensión o eliminación del gen antijurídico. En esencia, es la característica primordial que lo diferencia de una afectación permanente.

De manera ilustrativa, un daño continuado ocurre en el caso en el que una persona esté sometida a tratos denigrantes contra su voluntad y su alimentación consista en lo necesario para que no muera por dos años. Al terminar este tiempo, esta persona sufrirá grandes menoscabos en su sistema digestivo. Es claro que la causa dañosa se prolongaba conforme la persona se encontraba bajo los tratos denigrantes. En síntesis, lo que importa en un daño continuado es que el hecho generador se renueve de forma constante y sin interrupciones, pero con la posibilidad de que sea reversible.

En Ecuador, la jurisprudencia es escasa, por lo que no ha existido análisis de la figura, a pesar de que han existido argumentos alineados a esta categoría. El primer ejemplo dentro de esta categoría se presentó en C. con Banco Pichincha. En este caso, el expresidente R.C. demandó por daño moral a un banco ecuatoriano por incluirlo en un registro de morosos y en una central de riesgos crediticios, a pesar de no haberse demostrado la existencia de una deuda. Al respecto, la Corte Nacional de Justicia, sin afirmar la existencia ni analizar la figura del daño continuado, de manera enfática afirmó que:

“[E]n las obligaciones que nacen de actos o hechos sucesivos o periódicos, la prescripción se cuenta siguiendo la regla general, pero tomando como referencia cada acto. El acto ilícito en este caso se originó en la información periódica que el Banco proporcionaba a la Central de Riesgos (énfasis añadido)" $"$.

\footnotetext{
${ }^{59}$ Causa n. ${ }^{\circ} 1255 / 2008$ (2007).

${ }^{60}$ Reglero (2008), p. 1249.

${ }^{61}$ C. con Banco Pichincha (2012).
} 
A pesar de que el caso fue bastante discutido por el monto de la indemnización y la inexistencia de análisis alguno del artículo 2235 de la prescripción de la acción por daños extracontractuales, el entendimiento de la Corte Nacional de Justicia respecto a la concepción de este tipo de actos fue el correcto. En la misma línea, el Tribunal Supremo español confirma esta afirmación, cuando menciona que:

"Los daños producidos por la inclusión indebida de datos personales en un fichero de solvencia patrimonial tienen naturaleza de daños continuados. Como hemos declarado en sentencias anteriores, la causa que origina la intromisión en el derecho al honor (la imputación de ser moroso) persiste durante el tiempo en su eficacia potencialmente lesiva del honor ajeno hasta que no se cancela o se produce la baja del demandante en los citados registros" ${ }^{\prime 2}$.

Otro ejemplo de la jurisprudencia ecuatoriana en el que se evidencia un daño continuado se advierte en S. con la Corporación Financiera Nacional y otro. Por una deuda adquirida por la CFN en el año 1998, se siguió un proceso coactivo al actor en el año 2003 y como medida cautelar se ordenó el embargo de su "Hacienda la Ruidosa", que se dedicaba a la producción, cosecha y venta de fruta. De los autos, se conoce que el demandante llegó a un acuerdo con la CFN para el pago de la obligación en el mismo año, y a pesar de esto se negaron a entregar el inmueble, aprovechando la producción hasta el año 2008. Inclusive, se probó que la propiedad fue destruida por el mal manejo del equipamiento y la tierra, generando que se convierta en un lote baldío.

En este caso, se demuestra que la retención indebida, igual que el mal manejo durante el tiempo del bien, generan un daño continuado. La Corte Provincial del Guayas, ratificó la sentencia de primer nivel señalando que los "hechos que originan las acciones incoadas no han cesado y más bien continúan vigentes" ${ }^{63}$.

Así, se ha dejado claro que la categoría de daño permanente o duradero no es igual a la del continuado. El primero de ellos es una afectación consumada o instantánea que tiene efectos prolongados en el tiempo, mientras que el segundo involucra un hecho generador y un efecto continuo o sucesivo con un criterio de reversibilidad. Se ha establecido que en un menoscabo continuado es importante que no exista una interrupción de la causa en el tiempo, porque siempre debe existir el acto generador día a día. Entonces, se puede afirmar que el ordenamiento jurídico ecuatoriano ha conocido casos de daño continuado, a pesar de no haber delimitado y analizado esta categoría.

\footnotetext{
${ }^{62}$ Causa n. ${ }^{\circ}$ 2509/2011 (2014).

${ }^{63}$ S. con CFN (2011).
} 


\section{El daño oculto, tardío o sobrevenido}

En la clasificación de daños según su consumación en el tiempo cada categoría tiene su propia realidad. Por ello, existen características y dificultades propias cuando la afectación es oculta o tardía. Esta sección, para comprender y cimentar las bases del conocimiento, se fundamenta de doctrina y jurisprudencia comparada en donde se ha reconocido la figura, ya que, como se verá más adelante, el desarrollo del tema ha sido desaprovechado en Ecuador.

Algunos autores sostienen que este tipo de prejuicios son "aquellos que, guardando relación de causa a efecto, con el evento dañoso primitivo, se manifiestan con posterioridad" a su resolución y sin tomarlos en cuenta ${ }^{64}$. Sin embargo, esta concepción es bastante restringida, dado que pueden existir dos formas en las que se exteriorizan ${ }^{65}$. Por una parte, aquellos que se manifiestan después de transcurrido un cierto tiempo desde el acaecimiento del evento dañoso ${ }^{66} \mathrm{y}$, por otra, los que aparecen con posterioridad a la manifestación de un efecto dañoso primigenio ${ }^{67}$.

Este criterio ha sido acogido por el Tribunal Supremo español en R. con Zurich S.A. en el que el tribunal afirmó que este tipo de daños abarca nuevas afectaciones que aparecen con posterioridad a la producción de una manifestación inicial, en los que no importa si ha sido indemnizada o transada la afectación primaria, con lo cual la cosa juzgada no afectaría a la manifestación de daños posteriores, al ser considerados como ocultos o diferidos ${ }^{68}$.

$\mathrm{El}$ análisis de estas categorías es precario en Ecuador, pero han existido casos en los que se evidencian al menos indicios de que ha habido daños ocultos o tardíos. El caso C. y B. con Conclina ${ }^{69}$ es uno de ellos. Este caso versó sobre una supuesta negligencia dentro del Hospital Metropolitano de Quito, el día del nacimiento de una niña en 1978. Acorde a los hechos relatados en la demanda, en el año 2001, el padre de la niña obtuvo la nacionalidad americana, y para que sus hijos pudieran acceder a ella, la embajada ordenó exámenes de ADN. La prueba realizada en su hijo confirmó la paternidad, mientras que la prueba de su hija salió negativa. Tras la sorpresa, la madre decidió realizarse el mismo examen con un resultado igual. Por lo tanto, los padres dedujeron que su hija fue intercambiada con otra nacida viva en la institución hospitalaria 23 años atrás, y decidieron demandar una indemnización de daño moral por las afectaciones que esto les generó.

El Juzgado Quinto de lo Civil, que podría haber realizado un análisis del daño y su manifestación en el tiempo, no entró a analizar el fondo de la disputa, y, sin perjuicio del resultado final, perdió la oportunidad de actualizar

\footnotetext{
${ }^{64}$ YzQuierdo Tolsada (1993), p. 183.

${ }^{65}$ Torralba (2014), pp. 11-13.

${ }^{66}$ Reglero Campos (2008), pp. 1283-1285.

${ }^{67}$ Cavanillas (2013), pp. 13327-13331.

${ }^{68}$ Causa n. ${ }^{\circ} 4331 / 200$ (2007).

${ }^{69}$ C. y B. con Conclina C.A. (2004).
} 
criterios jurisprudenciales de interpretación en instituciones como la prescripción. En su lugar, ésta sirvió como fundamento para negar el reclamo, toda vez que aceptó la excepción interpuesta por la demandada, al considerar que:

"[t]anto de la demanda cuanto de las pruebas presentadas por la parte actora se desprende que el hecho que da inicio al presente enjuiciamiento sucedió el 6 de mayo de 1.987, es decir hace más de cuatro años"70.

Es evidente que este caso versó sobre una afectación que se evidencia varios años después del hecho generador. Por eso, de manera categórica se afirma que se trató de un daño oculto, por lo que el cómputo de la prescripción no debió contarse desde el hecho dañoso.

En el mismo sentido, se puede hablar de E. con L. ${ }^{71}$, proceso que versó sobre un error médico. El 14 de julio de 2001, nació un bebé que fue identificado por el departamento de neonatología con sexo "indeterminado"; un supuesto caso de seudohermafroditismo. Por esta razón, de manera provisional, se le asignó el sexo masculino sobre la base de un ecosonograma. Para esclarecer de manera definitiva el sexo del recién nacido, se ordenó un examen de cariotipo cromosómico. El encargado de interpretar este examen fue el doctor L., recomendado por su experiencia en casos similares. La demandante sostuvo que el doctor leyó los resultados del examen de cariotipo, interpretando que el "Cariotipo Normal 46XX" correspondía al sexo masculino. Por lo tanto, se le practicaron 3 cirugías al recién nacido, en los años 2001, 2004 y 2009, para así determinar su sexo como masculino. El problema se presentó cuando el niño entró en la adolescencia, y en el año 2014, le brotaron senos con una aureola de mujer desarrollada y experimentó un ciclo menstrual por su pene. La parte actora alegó que el demandado interpretó de manera incorrecta el examen de cariotipo 14 años atrás, generando como consecuencia que el sexo determinado para el recién nacido fuese incorrecto, e inició un reclamo por daño moral.

El análisis que se encuentra en este caso es mucho más avanzado al anterior. En primera instancia el juez rechazó la demanda por haber operado la prescripción. Por el contrario, en apelación, la Corte Provincial de Pichincha determinó que:

"En esta clase de casos (daño moral), no se puede considerar para efectos de prescripción tiempos matemáticos fríos, como se lo ha hecho, al considerar la fecha de la última operación y contrastarlo con la fecha de la citación (20 de enero del 2015), para desde ahí argumentar una prescripción, pues la doctrina nos enseña que en estos casos debe contabilizarse a partir de la fecha en que estos efectos se evidencian como tales.. ${ }^{.72}$.

\footnotetext{
${ }^{70}$ C. y B. con Conclina C.A. (2004).

${ }^{71}$ E. con L. (2019).

${ }^{72}$ E. con L. (2018).
} 
Sin duda alguna, la Corte realizó una referencia a la figura de daños ocultos o tardíos, donde lo que importa es la fecha en la que se manifiestan las afectaciones. La decisión fue revisada por la Corte Nacional de Justicia, pero, esta no fue casada. El problema radica en que la Corte Nacional confundió los daños ocultos con los daños continuados cuando afirmó que:

"Este tribunal de casación considera pertinente establecer que, en casos concretos como el presente, en el que, en secuencia de tiempos y acontecimientos se produce un daño continuado, el plazo de prescripción establecido en el artículo 2235 del Código Civil debe contarse desde que se produjo el último de los hechos dañosos, plasmado en la manifestación material de los efectos de todos los diagnósticos e intervenciones médicas en la víctima y la repercusión de aquellos en su vida, efectos exteriorizados, en este caso, en agosto del año 2014" (énfasis añadido) ${ }^{73}$.

Esta interpretación genera confusión, toda vez que los hechos del caso E. con L. indicaban una hipótesis de daño oculto o tardío. Por eso, es preciso diferenciar los daños ocultos de los continuados, sobre la base de los hechos antes mencionados. Por un lado, en el razonamiento expuesto por la Corte Provincial de Pichincha, se consideró que la afectación se manifiestó mucho tiempo después del hecho generador del daño, es decir, los efectos dañosos se verificaron con posterioridad a la interpretación de examen de cariotipo cromosómico y las operaciones realizadas en el menor.

Por otro lado, la postura de la Corte Nacional de Justicia fue que la acción u omisión que generó la afectación se prolongó en el tiempo, es decir que la causa del daño renovaría sus efectos de manera constante hasta manifestarse en el año 2014. No obstante, este criterio no tiene asidero alguno, puesto que en el caso no se evidencia una renovación periódica de la causa del daño. En estricto sentido, el hecho generador del daño ocurrió varios años en el pasado y su manifestación se dio con posterioridad a este.

De esta manera, se ha dejado claro que el daño oculto, tardío o sobrevenido es aquel que evidencia una afectación después del hecho ilícito. Se entiende que existen dos formas en las que este puede manifestarse, la primera es tras una leve manifestación primigenia, y la segunda sin que verse afectación previa. Asimismo, se afirma que esta figura ha sido reconocida y acogida en el derecho comparado. Finalmente, se puede sostener que en Ecuador han existido casos de daño oculto en el que las cortes han desperdiciado la oportunidad de ahondar en esta figura o la han entendido de forma equivocada.

\footnotetext{
${ }^{73}$ E. con L. (2019).
} 


\section{El daño contingente}

Si bien esta figura es tan antigua como el Código Civil, se ha decidido darle importancia dentro de esta clasificación por sus características peculiares, ya que no pertenece a ella. El daño contingente está recogido en el texto de los artículos 2236 y 2237 del Código Civil. Esta figura es una innovación jurídica para la época, que toma como inspiración el Digesto y las Siete Partidas ${ }^{74}$. Se puede afirmar que el daño contingente se fundamenta en el adagio "más vale prevenir que lamentar", toda vez que se busca evitar y cautelar los infortunios antes que resarcirlos. Por esto, de forma apropiada, Corral ha denominado a esta categoría como un sistema de responsabilidad preventiva, que busca anticiparse a la ocurrencia de un menoscabo ${ }^{75}$.

Por lo mencionado, se entiende que en estricto sentido no se habla de un daño, ya que no se ha materializado una afectación. $\mathrm{Al}$ respecto, la RAE define a la palabra "contingente" como "algo que puede o no suceder" Entonces, se deduce que se habla de situaciones en las que existe un riesgo o amenaza de que un daño real se produzca. Sin embargo, esto no implica su certeza ${ }^{77}$. Esto, hace pensar si en realidad esta figura debe ser estudiada por el derecho de daños. En este sentido, se expondrá cómo la doctrina ha concebido al daño contingente, y una postura propia que pretende innovar este entendimiento.

248 Según el artículo 2236 del Código Civil, los elementos necesarios para que se configure el daño contingente son:

1) la amenaza de daño;

2) el nexo de causalidad;

3) un criterio de culpabilidad; y,

4) un legitimado activo característico ${ }^{78}$.

El primer requisito de la amenaza se configura, como lo dice Diez Schwerter, al "existir indicios de [...] inminente daño, capaces de producir un justo motivo de temerlo"79. El segundo, se evidencia si

"[1]a amenaza del daño [...] [tiene] como causa un comportamiento descuidado del demandado. Esta vinculación coincidirá normalmente con la relación de causalidad que existirá entre el daño que se producirá y la conducta negligente del responsable" ${ }^{80}$.

${ }^{74}$ Diez Schwerter y Delgado Schneider (2003), p. 144.

${ }^{75}$ Corral (2003), pp. 355-360.

${ }^{76}$ Diccionario de la Real Academia Española (2020), "contingente".

${ }^{77}$ Alessandri (2015), pp. 159-160.

${ }^{78}$ Artículo 2236, Código Civil, de 2019: "Por regla general se concede acción popular en todos los casos de daño contingente que por imprudencia o negligencia de alguno amenace a personas indeterminadas. Pero si el daño amenazare solamente a personas determinadas, sólo alguna de éstas podrá intentar la acción".

${ }^{79}$ Diez Schwerter (2016a), p. 137.

${ }^{80}$ Corral (2003), p. 328. 
El tercero es el elemento subjetivo intencional de la conducta, ya que el artículo analizado expresa la necesidad de "imprudencia o negligencia", es decir, la culpa ${ }^{81}$. Sin embargo, se entiende que también aplica en la falta de diligencia con intencionalidad que sobrevenga el daño, es decir, el dolo ${ }^{82}$. Y, el cuarto se verifica cuando el daño sea temido por personas determinadas o indeterminadas. Lo característico de este requerimiento es el tipo de acción que se concede respecto de personas indeterminadas, ya que se les otorga una de carácter popular.

Respecto de las pretensiones, "mal podría pedirse y/o decretarse una reparación in natura o por equivalencia (sea o no dineraria) de un daño contingente" 83 , debido a que el efecto dañoso no se ha verificado. Teniendo en cuenta que la ley no determina cuáles serían los remedios en este tipo de “daños", podría afirmarse que siempre serán encaminadas a evitar que el suceso temido ocurra. Al respecto, las medidas a adoptarse "serán multiformes dependiendo de la naturaleza del daño y del modo en que está amenazando a la víctima" 84 .

Asimismo, se deben tener en cuenta los incentivos que recaen en el artículo 2237 en el caso de acciones populares ${ }^{85}$. El principal requisito para que operen estos es que la demanda "pareciere fundada", pues de ser el caso, le corresponderá al actor una "indemnización de todas las costas de la acción y se le pagará lo que valga el tiempo y diligencia empleada en ella”, además de una remuneración específica si la ley contemplara una. Cabe preguntarse, qué pasaría en casos en los que la demanda pareciere fundada, pero es de acción personal. En ese caso, se le deberían indemnizar las costas de la acción, ya que el actor ha sufrido un empobrecimiento injustificado a causa del inminente daño.

Respecto a la prescripción de daños contingentes, la doctrina ha establecido una postura a partir de una concepción global del Código Civil. Se ha entendido que, al ser una figura en la que no se evidencia afectación alguna, no podría utilizarse, en su totalidad, el mandato del artículo 2235. En este sentido, el plazo de prescripción será el mismo (4 años). Sin embargo, su dies a quo no podrá ser "desde la perpetración del acto", ya que por sus características no existiría ningún acto ni afectación. En este sentido, los comentaristas del Código Civil han utilizado figuras similares que contiene este cuerpo normativo que puedan dar un inicio a este plazo. Al respecto, se puede observar la disposición del inciso $2 .^{\circ}$ del artículo 992 respecto de

${ }^{81}$ Diez Schwerter (2016a), p. 141.

${ }^{82}$ Corral (2003), pp. 357-358.

${ }^{83}$ Diez Schwerter (2016a), p. 147.

${ }^{84}$ Corral (2003), p. 362.

${ }^{85}$ Artículo 2237, Código Civil, de 2019: "Si las acciones populares a que dan derecho los artículos precedentes parecieren fundadas, será el actor indemnizado de todas las costas de la acción, y se le pagará lo que valgan el tiempo y diligencia empleados en ella, sin perjuicio de la remuneración específica que conceda la ley en casos determinados". 
las acciones posesorias, que prescribe que: "[l]as dirigidas a precaver el daño no prescriben mientras haya justo motivo de temerlo" ${ }^{\text {" }}$. Este criterio ha sido propuesto, debido a que si la amenaza es latente, ese sería el momento en el que correrá el tiempo de prescripción del daño contingente ${ }^{87}$.

No obstante, a partir de la lectura del artículo 2236 del Código Civil, el elemento más importante de este tipo de daño es la exigencia de una amenaza inminente con justo temor de sufrirlo ${ }^{88}$. Con esta premisa, parece ser que los requisitos que prevé la norma son parecidos, por no decir idénticos a los de la justicia cautelar, que busca "prevenir los daños [...] que puedan derivarse de una situación anormal", mediante un proceso autónomo ${ }^{89}$. Estos requisitos son: fumus boni iuris y periculum in mora. El primero de ellos se traduce como la apariencia de buen derecho, y es un "presupuesto esencial y suficiente", según ciertos autores ${ }^{90}$. En el caso planteado, éste se evidenciaría por la contravención al deber general de responsabilidad y cuidado que propende la máxima neminem laedere. Específicamente, se lo verificaría con la amenaza del daño. Respecto al segundo, el peligro por el retardo busca su fundamento en las características de urgencia, necesidad y alcance de la situación que se busca prever ${ }^{91}$. Este requisito se verificaría por la inminencia del daño y su alcance, en el que será mejor evitar una situación dañosa, que repararla.

Así las cosas el estudio de la prescripción pierde interés, dado que si en este tipo de daños, uno de los requisitos es la inminencia y justo temor de 250 sufrir un daño, no tiene sentido hablar de cuánto tiempo se tiene y desde cuándo comienza su cómputo para reclamar un daño contingente en la vía judicial. Se cree que esta es la razón por la que el legislador no especificó una solución determinada para esta figura peculiar. En Ecuador,

"[l]a jurisprudencia nacional no muestra evidentemente referencia alguna a la acción por daño contingente, por lo que se puede afirmar su ninguna, o muy escasa aplicación práctica" ${ }^{92}$.

Así, se presumiría un desconocimiento "casi absoluto de esta sección"93. Por ello, este apartado pretende iniciar con el análisis de esta figura aprovechando el tema planteado de la prescripción en la acción por daños extracontractuales.

${ }^{86}$ Artículo 992, Código Civil, de 2019.

${ }^{87}$ Diez Schwerter (2016a), p. 151 y Corral (2003), p. 362.

${ }^{88}$ Artículo 2236, Código Civil, de 2019: "Por regla general se concede acción popular en todos los casos de daño contingente que por imprudencia o negligencia de alguno amenace a personas indeterminadas. Pero si el daño amenazare solamente a personas determinadas, sólo alguna de éstas podrá intentar la acción".

${ }^{89}$ Devis Echandía (2017), pp. 147 y 181.

${ }^{90}$ Chinchilla (1993), p. 172.

${ }^{91}$ Calamdrei (1945), pp. 41-42.

${ }^{92}$ A. y otros con Chevron Corporation (2012).

${ }^{93}$ Diez Schwerter (2016b), p. 276. 


\section{LA PRESCRIPCIÓN \\ Y SU RELACIÓN CON EL DE DERECHO DE DAÑOS}

En el derecho las instituciones se relacionan, y una vez estudiado el elemento del daño y sus distintas categorías de consumación en el tiempo, resulta conveniente analizar el comienzo de la prescripción en estos tipos de daños. A partir de esta descripción, se expondrá el fundamento y los requisitos necesarios de la prescripción [IV.1]. Asimismo, se profundizará en las soluciones planteadas en el derecho comparado a estas distintas clases de daños [IV.2]. $\mathrm{Y}$, se observará a la prescripción en el ordenamiento ecuatoriano, en el que se podrá notar que no existe un mecanismo con aceptación absoluta para contabilizar su dies a quo, de manera tal que es necesario el planteamiento de una solución al respecto mediante un correcto entendimiento del artículo 2235 del Código Civil [Iv.3].

\section{Fundamento y propósito de la prescripción extintiva o liberatoria}

La prescripción aparece en el Código Civil con una doble dimensión: una positiva que permite adquirir las cosas que se han poseído por un determinado tiempo (usucapión); y, una negativa por la cual se pueden extinguir acciones y derechos como consecuencia de la falta de ejercicio del titular ${ }^{94}$. Esta sección se enfocará en esta última, que se refleja en el artículo 2392 inciso $1^{\circ}$ del Código Civil que afirma que:

"[p]rescripción es un modo [...] de extinguir las acciones y derechos ajenos [...] por no haberse ejercido dichas acciones y derechos, durante cierto tiempo y concurriendo todos los demás requisitos legales" ${ }^{95}$.

Para la doctrina, la prescripción es una institución de orden social que "constituye un medio de liberación, por el cual la obligación civil se transforma en natural, luego de cumplirse los plazos fijados por la ley" ${ }^{\prime 6}$. En consecuencia, la extinción afecta solo a la acción, mas no al derecho ${ }^{97}$. Con este orden de ideas, es preciso indicar cuál es el objetivo de una acción. Se puede sostener que, "todo derecho que al individuo se le reconoce u otorga, se encamina a la satisfacción de una necesidad suya" ${ }^{98}$ y la acción busca el mismo propósito en el ámbito judicial ${ }^{99}$. Por lo tanto, si la acción no es ejercida se entenderá que el derecho no es de interés y perderá su razón de ser.

\footnotetext{
${ }^{94}$ Parraguez (2016), pp. 357-359.

${ }^{95}$ Artículo 2392, Código Civil, de 2019.

${ }^{96}$ Moisset de Espanés (1968), p. 1.

${ }^{97}$ BORDA (2008), pp. 3-4.

${ }^{98}$ Ospina Fernández (2018), p. 466.

${ }^{99}$ Devis Echandía (2017), pp. 153-165.
} 
Este efecto extintivo se fundamenta en dos enfoques. El primero, como una sanción a la inactividad prolongada por no exigir lo que por derecho corresponde, es decir un castigo a la negligencia del acreedor; mientras que el segundo es la seguridad jurídica que genera el no dilatar la incertidumbre del deudor y la sociedad ${ }^{100}$. Para Planiol y Ripert estas consecuencias buscan respetar la equidad ${ }^{101}$. Por lo tanto, en el ámbito de la acción por daños extracontractuales, la prescripción se aplica cuando la víctima, de manera negligente, no impulsa un proceso para ser reparada. Como efecto, el ordenamiento sanciona su inactividad, negando la posibilidad de reclamar por la afectación generada.

Los requisitos para que opere la prescripción son:

1) la inacción del acreedor; $y$,

2) el transcurso del tiempo ${ }^{102}$.

Como se mencionó con anterioridad, el primer elemento se configura con el desinterés o con la existencia de negligencia del acreedor frente a la prestación debida. Al respecto, hay que tener en cuenta la etapa que Ospina denomina como 'inactividad forzada del acreedor', haciendo alusión a obligaciones sujetas a plazo o condición suspensiva en las que no corre la prescripción ${ }^{103}$. La razón es porque las obligaciones, en ambos casos, no son ejecutables ni exigibles $^{104}$.

Esta situación es importante porque también puede ocurrir en la acción 252 por daños extracontractuales. En estricto sentido, se pueden tener como ejemplo los daños continuados y los ocultos, en los que el acreedor se ve imposibilitado de iniciar su acción, sea porque desconoce la afectación o porque sigue produciendo sus efectos. Para este tipo de casos, la solución que se ha optado viene de la máxima romana contra non valentem agere praescriptio non currit, que significa que la prescripción no corre contra quien está imposibilitado para actuar ${ }^{105}$. Este criterio es acogido por quienes sostienen que la prescripción corre "desde el día en que el acreedor hubiera podido demandar a su deudor" ${ }^{106}$. Sin perjuicio de esto, la máxima romana es uno de los fundamentos de este trabajo, toda vez que se ha entendido que la interpretación clásica del artículo 2235 del Código Civil no la contempla, ya que éste propende una concepción limitada y restrictiva. Esta afirmación es incorrecta, porque como se verá más adelante, esta disposición, mediante una correcta interpretación, abarca todos los tipos de daños [infra IV.3].

El segundo requisito afirma que no sólo basta la inacción del acreedor, sino que se presume que el derecho ha sido abandonado o que la prestación

\footnotetext{
${ }^{100}$ Parraguez (2000b), p. 172.

${ }^{101}$ Planiol y Ripert (2005), p. 265.

${ }^{102}$ BORDa (2008), pp. 3-4.

${ }^{103}$ Ospina (2018), pp. 468-469.

${ }^{104}$ Parraguez (2000a), pp. 168-170.

${ }^{105}$ Colin y Capitant (1939), p. 350.

${ }^{106}$ Pothier (2008), p. 229.
} 
ha sigo pagada ${ }^{107}$. Con esta finalidad, la ley es la que se encarga de señalar el tiempo que debe transcurrir para que se pueda presumir el desinterés o la negligencia del acreedor o el cumplimiento de la obligación ${ }^{108}$. Esto, guiado por el precepto de que el accionar del tiempo todo lo destruye ${ }^{109}$. En el caso que compete, el artículo 2235 del Código Civil es claro al establecer los "cuatro años" como el tiempo necesario para que prescriba la acción. El problema aparece cuando se ha intentado entender la frase "desde la perpetración del acto" para iniciar el cómputo de la prescripción, bajo el entendido de que se habla del cometimiento del hecho ilícito, y es en ese momento cuando el agraviado toma conocimiento y puede reclamarlo. Sin embargo, esa postura no funciona de manera adecuada en casos de daño oculto y continuado.

En síntesis, la prescripción es relevante en el derecho de daños. Esta institución busca extinguir las acciones de los derechos que no han sido ejercidas, sea por negligencia o por desinterés del deudor en el transcurso del tiempo. Asimismo, tiene como fundamentos la seguridad jurídica del deudor y de la sociedad, y es una sanción a la inactividad del acreedor. Con esto en mente, en la responsabilidad extracontractual debe evidenciarse una inactividad por cuatro años para que opere la prescripción, sin dejar de lado que el dies a quo dependerá de cómo se entienda la frase "desde la perpetración del acto".

\section{El comienzo del plazo de prescripción de la acción de daños en el derecho comparado}

En el derecho comparado existen distintos mecanismos para contabilizar el tiempo de prescripción en la acción por daños, varios de los cuales han sido reformados hace corto tiempo. En este sentido, se examinarán elementos normativos alejados de la tradición jurídica del Código Civil, como el derecho español y el derecho argentino, junto con ordenamientos con una tradición jurídica común a la ecuatoriana, como el derecho chileno y colombiano; sumando elementos recogidos del derecho alemán, así como del common law estadounidense. Por consiguiente, se encontrará un abanico de posibilidades respecto del inicio de la prescripción de la acción por daños que pueden servir de guía para la solución aplicable en el derecho ecuatoriano.

En la legislación española, existen dos formas en las que se ha determinado el dies a quo de la prescripción en la responsabilidad extracontractual. La primera que se evidencia es la regla general contenida en el artículo 1968 n. ${ }^{\circ} 2$ del código civil español. Este artículo establece que el conteo de la prescripción comenzará "desde que lo supo el agraviado" 110 . Esta solución se puede aplicar tanto para daños consumados (se incluyen daños permanentes),

${ }^{107}$ Ospina (2018), p. 469.

${ }^{108}$ Moisset de Espanés (1987), p. 3.

${ }^{109}$ Alessandri (1991), pp. 145-148.

${ }^{110}$ Artículo 1968 numeral 2, Código Civil español, de 1889. 
como para aquellos ocultos o sobrevenidos. Esta regla es desarrollada por considerar que cualquier otra vulneraría la seguridad jurídica que busca la prescripción ${ }^{111}$.

La segunda forma deviene de la jurisprudencia española, que ha entendido que, por la forma en la que se manifiestan los daños, no existe una solución única. Por ejemplo, cuando se habla de daños continuados se ha determinado que el comienzo de la prescripción corre desde el momento en que se produce el resultado definitivo de la afectación ${ }^{112}$. Esta solución está encaminada a conocer el monto total de la indemnización, es decir, cuando sea improbable la continuación, el agravamiento o la aparición de nuevos daños ${ }^{113}$.

Respecto del ordenamiento argentino, la regla ha sido recientemente modificada por la expedición del nuevo Código Civil y Comercial de la Nación. $\mathrm{El}$ artículo 2554 de este cuerpo normativo establece que "el transcurso del plazo de prescripción comenzará el día en que la prestación es exigible" ${ }^{114}$. Sin embargo, la ley no indica desde cuándo la prestación por daños es exigible. La Corte Suprema de Justicia argentina ha interpretado que el inicio de la prescripción es el momento en que la responsabilidad existe y por tanto la acción ha nacido ${ }^{115}$. En específico, cuando se ha producido el hecho ilícito; esto, sin perjuicio de las distintas categorías de daños ${ }^{116}$. En este sentido, se ha pronunciado la Corte Suprema de dicho país, estableciendo que la regla general del actual artículo 2254 no siempre se aplica, y de manera excepcio254 nal podrá determinarse un momento diferente dependiendo de la forma en la que se manifiesten los daños, hablando de daños ocultos o continuados en los que se computará desde que se manifieste el daño o la causa del daño desaparezca, respectivamente ${ }^{117}$.

Cuando se habla de derecho chileno, al utilizar el mismo Código Civil con ciertas variaciones, existe una conexión mucho más cercana que las antes mencionadas. El artículo de la prescripción de la acción por daños extracontractuales tiene el mismo texto que el artículo 2235 del Código Civil. Por lo tanto, el cómputo de la prescripción se cuenta "desde la perpetración del acto" ${ }^{118}$. Al respecto, existe la misma discusión que se plantea en el presente trabajo, ya que existen posiciones que defienden la postura clásica fundacional u objetiva, frente a una propuesta actual o subjetiva.

La interpretación fundacional se inspira en la posición de Alessandri, quien sostenía que

${ }^{111}$ ARMAdÀ (2015), pp. 51-55.

${ }^{112}$ Causa n. ${ }^{\circ} 1580 / 2014(2009)$.

${ }^{113}$ Causa n. ${ }^{\circ}$ 170/2005 (2009).

${ }^{114}$ Artículo 2554, ley n. ${ }^{\circ} 26.994$ [Código Civil argentino], 2014.

${ }^{115}$ S. M. E. S y Cía. S.C.A. con Provincia de Buenos Aires (2002); T. D con Estado Nacional

(1999); y, Constructora Barcala con Banco Central de la República Argentina (1997).

${ }^{116}$ Moisset De Espanés (2004), p. 399.

${ }^{117}$ G. R. con Río Negro (2010).

${ }^{118}$ Artículo 2232, ley n. ${ }^{\circ} 18525$ [Código Civil chileno], de 1986. 
"la acción para obtener la reparación del daño causado por un delito o cuasidelito se extingue por prescripción de cuatro años contados desde la perpetración del acto, es decir desde el día en que se cometió el hecho doloso o culpable y no desde aquél en que se produjo el daño, si ésta y el hecho no son coetáneos"119.

En los últimos años, varios autores han abrazado esta postura ${ }^{120}$, en especial, Ferrada quien, tras realizar un estudio de las normas y la jurisprudencia del ordenamiento chileno para encontrar el verdadero sentido del artículo respecto a su dies a quo, llegó a la conclusión que el artículo 2232 era sumamente claro y no aceptaba más interpretaciones que aquellas que cuenten el plazo de prescripción a partir del hecho ilícito ${ }^{121}$. Un claro ejemplo de esta posición es la acogida por la Corte Suprema cuando aplica el criterio fundacional del artículo, entendiendo que "la prescripción extintiva se inicia en la fecha exacta en que se consumó el hecho generador del daño, no antes ni después" ${ }^{122}$. Esta concepción es de evidente carácter conservador respecto de los alcances del artículo estudiado, porque a partir de ella el Código Civil no aceptaría otra interpretación ni necesitaría una modificación.

Sin embargo, no es la única posición que han abrazado la doctrina y jurisprudencia chilena, ya que han existido fallos y comentaristas del Código Civil que se alejan de esta concepción restrictiva, cuando la hipótesis cambia y no es tan fácil de resolver. Por ejemplo, Barros afirma que lo

“correcto es contar el plazo de prescripción desde que ocurra el daño, ya que desde ese instante surge el delito civil y el derecho a la reparación, como ha tendido a afirmar también la doctrina"123.

La misma línea sigue Corral, al mencionar la problemática de los daños que tienen una prolongación en el tiempo y su dificultad de encontrar el inicio de la prescripción ${ }^{124}$. Asimismo, cita una sentencia de la Corte de Apelaciones de Santiago que afirmó que en casos de daños con una serie encadenada de acciones la prescripción se cuenta "desde que termina el periodo de ejecución"125. Respecto de daños ocultos, la Corte Suprema de dicho país afirmó que "para que nazca el derecho a pedir indemnización es necesario que se haya producido el daño, antes no hay derecho para demandar perjuicios" ${ }^{\prime 26}$. Por eso, Domínguez sostiene que "debería entenderse así fijada definitivamente

\footnotetext{
${ }^{119}$ Alessandri (2015), p. 377.

${ }^{120}$ Tapia (2016), p. 1941 y Vergara (2004), pp. 55-66 o Vergara (2011), pp 25-38.

${ }^{121}$ Ferrada (2012), pp. 35-60.

${ }^{122}$ E. con Fisco de Chile (2018).

${ }^{123}$ Barros (2006), p. 924 y Domínguez Águila (2020a), p. 378.

${ }^{124}$ Corral (2003), pp. 355-360.

${ }^{125}$ RDJ, t. LXXVIII, sec. 5ta (1981), citado por CorRal (2003), p. 350.

${ }^{126}$ M. R. con Salud del Biobío (2020).
} 
la doctrina jurisprudencial en cuanto del plazo de prescripción de la acción indemnizatoria extracontractual" 127 .

La tradición jurídica del derecho colombiano también acogió el Código de Bello. A pesar de esto, el texto del artículo de prescripción es distinto al del Código Civil ${ }^{128}$, aunque está guiado por el mandato de contar la prescripción “desde la perpetración del acto". Distinto al caso chileno, el ordenamiento colombiano optó por la promulgación de la ley n. ${ }^{\circ} 472$ de 1998 que en su artículo 47 adhirió a un mecanismo más para el cómputo de la prescripción por daños. Se trata de la fecha en que

1) se causó el daño; y,

2) cesó la acción vulnerable causante del mismo ${ }^{129}$. $\mathrm{Al}$ respecto la sala de casación de la Corte Suprema de Colombia ha definido para qué tipos de daños se aplica cada una de estas reglas. Cuando la afectación es oculta o es continuada se computará la prescripción a partir de la fecha en que se causó el daño, que se entiende en perjuicios ocultos a partir de la fecha en que se manifiesta y en continuados desde su total configuración, es decir, un daño "efectivamente producido o consolidado". Por otro lado, en perjuicios inmediatos se computará el tiempo desde la fecha de acción causante ${ }^{130}$ (desde el cometimiento del hecho ilícito).

Tomando en cuenta los recientes cambios que ha tenido el ordenamiento jurídico alemán es importante desarrollar cómo se ha entendido la prescripción 256 para relaciones extracontractuales. Es evidente que el BGB alemán se ha inspirado en los principios de uniformidad y claridad del derecho privado europeo, que se han tomado de la Comisión Lando expresada en los Principios Europeos de Derecho de los Contratos $^{131}$. Esta influencia, sin duda se ha plasmado en la referida legislación que ha optado por unificar los tiempos de prescripción tanto en relaciones legales, contractuales y extracontractuales ${ }^{132}$. A partir de esta lógica el ordenamiento alemán opta por un régimen subjetivo de prescripción unificado. Debe destacarse que el régimen de entendimiento siempre fue subjetivo previo a la reforma, por lo que se inspiraron en una concepción marcada que amplificó su ámbito de aplicación a las relaciones contractuales y legales. No obstante, en busca de esta regulación común, ambas legislaciones comparten un texto igual para la prescripción. Según el BGB alemán, se establece que

"el comienzo de la prescripción se inicia en el momento en que el acreedor tenga conocimiento de las circunstancias que pueden dar lugar al ejercicio de la pretensión y de la persona obligada a hacer frente a ella"133.

\footnotetext{
${ }^{127}$ Domínguez Águila (2020b), pp. 252-253.

${ }^{128}$ Artículo 2358, ley n. ${ }^{\circ}$ 57, de 1887 [Código Civil colombiano], de 1873.

${ }^{129}$ Artículo 47, ley n. ${ }^{\circ} 472$, de 1998.

${ }^{130}$ Caso n. ${ }^{\circ}$ SC016-2018 (2018).

${ }^{131}$ Albiez Dohrmann (2002), pp. 1154-1155.

${ }^{132}$ WACKE (2013), pp. 709-710.

${ }_{133}$ Albiez Dohrmann (2002), p. 1156
} 
Por lo tanto, el ordenamiento alemán siempre entendió la importancia del daño como un requisito para la existencia de responsabilidad civil, situación que debe influir siempre en el análisis de la prescripción por acción de daños.

Finalmente, en el common law estadounidense, el enfoque estricto no es una solución correcta. Esto lo ha entendido el derecho anglosajón desde inicios del siglo $\mathrm{xx}^{134}$. La institución, que el en derecho continental se conoce como prescripción, en el common law son los statutes of limitation, la que también se aplica en las acciones por ilícitos civiles (torts) ${ }^{135}$. En el torts law (derecho de daños del derecho común), la regla general para computar la prescripción es la fórmula "when the cause of action arises", es decir, cuando surge la causa de la acción ${ }^{136}$. Esta hace referencia a la forma de cómputo desde la verificación del acto causante del daño. Sin duda, la regla funcionó de manera correcta hasta que se evidenciaron casos de daños ocultos por negligencia médica o exposición a sustancias tóxicas ${ }^{137}$. En 1949, el Tribunal Supremo de los Estados Unidos, en U. v. T, estableció una excepción al statute of limitation de la ley federal de responsabilidad de los empleadores mediante una discovery rule, que se caracteriza por evitar el inicio de la prescripción hasta que la víctima del daño lo descubra (discover) ${ }^{138}$. El fundamento fue que el statute of limitation no cumplía con el objetivo de resolver conflictos que atenten a la seguridad jurídica, y que en su lugar era un obstáculo injustificado para el ejercicio de las acciones de las víctimas por hechos ilícitos ${ }^{139}$.

En conclusión, puede verse que existen varias soluciones acogidas bajo el derecho comparado respecto a la forma de computar el inicio de la prescripción en la acción por daños. Estas soluciones van de la mano con el principio transversal de la responsabilidad extracontractual, que es resarcir todos los daños causados. Con esto en mente, es preciso proponer una solución acorde a los distintos tipos de daños según su consumación, para que el artículo 2235 del Código Civil pueda responder a una óptica actual y acorde a la evolución del derecho de daños.

\section{La prescripción en el ordenamiento jurídico ecuatoriano: hacía una propuesta actual del artículo 2235 del Código Civil}

Como es conocido, el ordenamiento jurídico ecuatoriano acogió el Código de Bello como suyo. En 1855, la Corte Suprema de Justicia, encargada de la redacción de un código propio declinó la misión afirmando que

\footnotetext{
${ }^{134}$ PeÑa LóPeZ (2011), pp. 13-14.

${ }^{135}$ Green (1988), pp. 5-6.

${ }^{136}$ Bain y Colella (2004), p. 7.

${ }^{137}$ Peña López (2011), pp. 13-14.

${ }^{138}$ U. con T. (1947).

${ }^{139}$ Narula (2010), pp. 8-10.
} 
"sus doctrinas y aun su estilo [del Código Civil chileno] podrían ser adoptados por nosotros, haciendo solamente una que otra variación, que la diferencia de circunstancias y el bien de la claridad hicieran necesarias" ${ }^{140}$.

La creación de Bello tuvo como antecesores tres bocetos en los que el articulado y su estructura varió notablemente.

El texto del año 1841-1845 fue una recopilación de normas creadas hasta la fecha con cierta adaptación de lenguaje sencillo, y donde no existía norma referente a la prescripción de la acción por daños ${ }^{141}$. Respecto del segundo proyecto de 1847 , se trató de conservar la tradición jurídica española ${ }^{142}$, y se agregó un artículo específico en la sección de responsabilidad extracontractual conforme a la cual el tiempo de prescripción se contaría "desde el día en que la persona a quien competen tuvo conocimiento del daño o dolo"143. Si bien el proyecto de 1853 se aleja del modelo español y se inspira en el Código Civil francés ${ }^{144}$, no existe una variación del texto en el artículo mencionado ${ }^{145}$.

El gran cambio aparece con la expedición del Código inédito de Bello en 1857. En su artículo 2332 cambia la idea del conocimiento de la víctima, ya que la prescripción se computará "desde la perpetración del acto".

Cabe recordar que el régimen de responsabilidad civil en el Ecuador sigue los lineamientos de las Siete Partidas de España y la Lex Aquilia del derecho romano en las que Bello se inspiró ${ }^{146}$. Además del contenido de la ley n. ${ }^{\circ} 171$ 258 reformatoria del Código Civil sobre reparación de daños morales ${ }^{147}$. Por lo tanto, se puede afirmar que el legislador siempre procuró que todo daño se indemnice, guiado por el precepto contenido en el artículo 2214 del Código Civil, por el que "[e]l que ha cometido un delito o cuasidelito que ha inferido daño a otro, está obligado a la indemnización" ${ }^{148}$. Es evidente que el objetivo del título de delitos y cuasidelitos del Código Civil es compensar cuando exista un daño que la víctima no está obligada a soportar.

A pesar de esto, la interpretación clásica del artículo 2235 del Código Civil afirma que "perpetración del acto" se refiere sólo al cometimiento del hecho ilícito, por lo que se contará el tiempo de prescripción desde ese momento. Esta postura se fundamenta en una interpretación restrictiva del articulado a partir de una definición general de las palabras según el lenguaje. También, se fundamentan en que Bello se alejó de la regla general de la prescripción

${ }^{140}$ JAKSIC (2003), p. 209.

${ }^{141}$ BeLlo (1887a).

${ }^{142}$ Velásouez Posada (2016), pp. 217-219.

${ }^{143}$ BeLlo (1887b), p. 579.

${ }^{144}$ Velásquez Posada (2016), pp. 217-219.

${ }^{145}$ BeLLo (1887c), p. 591.

${ }^{146}$ Velásquez Posada (2016), pp. 217-219.

${ }^{147}$ Ley n. ${ }^{\circ} 171$ [reformatoria del Código Civil sobre reparación de daños morales], de 1984.

${ }^{148}$ Artículo 2214, Código Civil. R.O. suplemento 46, de 24 de junio de 2005, reformado por última vez el 08 de julio de 2019. 
de su código como lo hizo en otros artículos ${ }^{149}$. No obstante, se olvida que en el derecho, muchas veces, las definiciones varían por elementos jurídicos esenciales que se han definido de manera distinta o que deben entenderse de forma diferente a través de la aplicación de las reglas generales para entender la ley.

A partir de esta explicación, lo más recomendable es cambiar la concepción que recoge el artículo 2235 del Código Civil en la actualidad, gracias a la falta de su aplicación en casos más elaborados donde el menoscabo puede manifestarse de distinta manera al daño inmediato o consumado. Así, ha quedado claro que, una variación a la regla no atenta contra los fundamentos de la prescripción, debido a que la seguridad jurídica y justicia que busca esta institución se refleja en la existencia de un tiempo de prescripción, mas no en su forma de cómputo ${ }^{150}$. Fundamento de esto, es lo que se observa en el derecho comparado, donde existe mecanismos diversos de solución para cada caso.

En un principio la regla del artículo 2235 del Código Civil fue aplicada de manera estricta, sin lugar a otras interpretaciones que contar el tiempo de prescripción desde el hecho ilícito. Esto se demuestra en el caso C. y B. con Conclina, donde se afirmó que de los actos de proposición "se desprende que el hecho que da inicio al presente enjuiciamiento sucedió el 6 de mayo de 1.987 , es decir hace más de cuatro años" ${ }^{151}$. De esta manera se aceptó la prescripción, sin realizar un análisis en el que se pueda evidenciar que se trataba de un daño oculto o tardío, ya que el resultado hubiese sido distinto. Por consiguiente, es necesaria otra interpretación del sentido de la ley, para armonizarla con los principios que rigen tanto la responsabilidad extracontractual como la prescripción, utilizando los elementos contemplados en el artículo 18 del Código Civil.

El primer paso es buscar el espíritu del artículo 2235 del Código Civil. El contenido de la norma regula la prescripción de las acciones por daños y busca establecer seguridad jurídica en las situaciones en las que el acreedor negligente o desinteresado no ha ejercido la acción de daños. Para ello, el precepto normativo dispone el tiempo de cuatro años, que se los contará a partir de la perpetración del acto. No cabe duda de que el espíritu del artículo es la seguridad jurídica.

Lo anterior, conduce al segundo paso, que es la interpretación literal de la norma mediante su sentido natural y obvio. Según la RAE, el término "perpetrar" se define como: "[c]ometer, consumar un delito o culpa grave"152. Resulta evidente que, no sólo se requiere la realización del hecho ilícito, sino también implica la consumación de sus efectos. Con esta premisa, en un daño

\footnotetext{
${ }^{149}$ Ferrada (2012), pp. 35-60.

${ }^{150}$ Moisset de Espanés (1987), p. 3.

${ }^{151}$ C. y B. con Conclina C.A. (2004).

${ }^{152}$ Diccionario de la Real Academia Española (2020), “perpetrar”.
} 
oculto los daños se consuman cuando la víctima los conoce. Incluso, esta concepción del término perpetrar va de la mano con la definición que se le ha dado al hecho jurídico, siendo "todo suceso de la naturaleza o del hombre que produce efectos de derecho" ${ }^{153}$. Hay que tener en cuenta que, en el caso de la responsabilidad civil extracontractual, los efectos jurídicos únicamente aparecerán cuando se evidencie la existencia de un delito o cuasidelito, en donde el daño es esencial. Además, de que el acto será jurídico a partir de una cualificación a posteriori, es decir, luego de la ocurrencia del hecho mismo que

“[...] [v]iene a ser 'jurídico' en cuanto el derecho, sobreviniendo con su propia valoración, dispone en vista de él determinadas consecuencias en el orden jurídico [...]"154.

Por lo tanto, la obligación de indemnizar como consecuencia del hecho jurídico ilícito sólo nacerá si existen todos los elementos de la responsabilidad.

Asimismo, debe tomarse en cuenta la interpretación lógica de la norma. El artículo in comento se encuentra ubicado en el título de los delitos y cuasidelitos, en el que se encuentra el régimen de responsabilidad extracontractual. En este sentido, su aplicación debe ir de la mano con la finalidad de la responsabilidad aquiliana. Como se ha expuesto con anterioridad, el objetivo es reparar todo daño que no debe ser soportado por la víctima, por lo tanto, 260 se corrobora la necesidad de la manifestación del daño para hablar de una obligación de indemnizar. En el mismo sentido, debe tomarse en cuenta el inciso $2^{\circ}$ del artículo 2414 del Código Civil, que manifiesta que la prescripción se cuenta desde el momento en que la obligación haya sido exigible ${ }^{155}$. En el presente caso, la obligación no sería exigible si se cuenta desde el cometimiento del hecho ilícito, toda vez que "sin daño no hay responsabilidad y sin responsabilidad no hay acción resarcitoria" ${ }^{156}$. La jurisprudencia ecuatoriana ha entendido esto a la perfección, lo que se demuestra cuando afirmó que "sin que exista responsabilidad, no puede operar la prescripción extintiva. No se extingue la nada o lo que no existe" (énfasis añadido) ${ }^{157}$. Es evidente que, quienes acogen la interpretación clásica del artículo 2235 olvidan la necesidad de todas estas características necesarias, como que un acto para que sea jurídico debe tener consecuencias otorgadas por el ordenamiento, o que para que exista responsabilidad el daño es esencial o que para que opere la prescripción de la acción, debe existir un derecho.

Para terminar, el método sistemático de interpretación indica que debe existir armonía entre las normas del ordenamiento jurídico. Cabe destacar

\footnotetext{
${ }^{153}$ Alessandri Rodríguez y Somarriva Undurraga (1961), p. 281 y Vodanovic (2001), p. 1.

${ }^{154}$ BARbero (1967), pp. 332-333.

${ }^{155}$ Artículo 2494, Código Civil, de 2019.

${ }^{156}$ Echevesti (1997), p. 547.

${ }^{157}$ M. L. con AECA (2004).
} 
que la Constitución de Ecuador, en su artículo 86 n. ${ }^{\circ}$ 3, reconoce la reparación integral del daño como un principio de aplicación a todo proceso jurisdiccional ${ }^{158}$. Este principio busca dejar a la víctima en la situación en la que estuviera sin la ocurrencia del daño. A partir de todo lo expuesto y de la aplicación de las normas interpretativas de la ley que el Código Civilrecoge, se puede llegar a la conclusión de que el artículo 2235 busca establecer seguridad jurídica mediante la prescripción de la acción por daños extracontractuales y que esta se computará desde que la obligación es exigible. Entonces, esta institución y su fundamento irán de la mano con la finalidad de la responsabilidad extracontractual, que es reparar todo daño que la víctima no esté obligada a soportar, en la que se procurará su reparación integral dejándola en la situación en la que estuviera si no hubiese existido la afectación.

Así, en casos de daños ocultos la frase "desde la perpetración del acto", no involucrará comenzar la contabilización del tiempo desde el hecho ilícito, porque no se puede sacrificar el derecho de la víctima en aras de una supuesta seguridad jurídica. Sobre la base de una interpretación acorde al espíritu de la norma, literal, lógica y sistemática del artículo 2235, se puede llegar a la conclusión que en daños ocultos o tardíos los términos "desde la perpetración del acto" involucran de manera obligatoria el conocimiento de la víctima del daño para el dies a quo de la prescripción.

El mismo ejercicio puede realizarse en daños continuados. Por ejemplo, en el caso S. A. con la CFN se afirmó que en daños continuados no puede aplicarse la regla "matemática fría" del artículo $2235^{159}$, porque en este tipo de daños "la prescripción debe contarse a partir del último acto de violación repetitiva, continua e ininterrumpida" 160 . En estos casos, es claro que la "perpetración del acto" hace referencia al último hecho y efecto dañoso.

En síntesis, cabe afirmar que en el daño oculto o tardío se debe contar el tiempo desde el conocimiento de la víctima, mientras que en el continuado o sucesivo el cómputo de la prescripción debe iniciarse desde el último hecho que genera el daño. Respecto al daño consumado o instantáneo se debe mantener la interpretación fundacional y el dies a quo será desde la verificación del hecho ilícito, al ser la hipótesis en la que la regla siempre ha funcionado y puede surtir plenos efectos.

Sin perjuicio de lo anterior, y abogando por una mayor claridad y seguridad, se plantea una posible reforma al texto actual del artículo 2235 del Código Civil, que contenga todos los aspectos considerados a lo largo de este trabajo. El texto que se propone es el siguiente:

"Art. 2235. Las acciones que concede este Título prescriben en cuatro años, contados desde que la obligación es exigible.

\footnotetext{
${ }^{158}$ Artículo 86 numeral 3, Constitución de la República del Ecuador, de 2020.

${ }^{159}$ S. con CFN (2011).

${ }^{160}$ LÓPEZ HERRERA (2007), pp. 152-155.
} 
Se entiende que la obligación será exigible:

(1) Desde el cometimiento del hecho ilícito en daños que se manifiestan de manera inmediata;

(2) Desde el último hecho dañoso en daños de producción sucesiva o continuada; $y$,

3) Desde que la víctima tuvo conocimiento en daños que se manifiestan tiempo después del hecho que los genero" ${ }^{161}$.

\section{Conclusiones}

El dies a quo de la prescripción en la acción por daños extracontractuales es un tema de discusión en Ecuador. Este trabajo fue realizado con el objetivo de buscar una respuesta actual para la concepción del artículo 2235 del Código Civil. La problemática se nutre del presupuesto material del daño como requisito indispensable de responsabilidad civil extracontractual. Así como, con las distintas categorías de daños según su manifestación en el tiempo, en las que se evidencian el daño continuado y el daño oculto; y, su íntima relación con la institución de la prescripción.

Respecto al elemento del daño y su importancia, se ha dejado claro que éste puede ser considerado como una condición inexorable de la responsabili262 dad civil, y que a su vez su reparación es el objeto del juicio de resarcimiento. Es decir, un elemento imprescindible. El daño será relevante cuando es jurídico, esto significa que el ordenamiento tutele o proteja diversidad de bienes jurídicos que en caso que se vean afectados corresponda una indemnización. En el mismo sentido, se ha establecido que existen tres requisitos para que pueda hablarse de daño jurídico resarcible. Estos son que el daño sea:

1) cierto;

2) que la afectación recaiga en un interés legítimo o lícito; y,

3) que el daño sea subsistente al momento de su reclamación.

De igual forma, se ha demostrado que existe una clasificación de daños según su consumación en el tiempo que no ha sido profundizada en Ecuador. En esta resaltan las categorías del daño consumado o instantáneo, el continuado o sucesivo y el oculto o tardío. Dentro del análisis de la primera categoría se enfatizó que un daño duradero o permanente no es sinónimo de continuado o sucesivo, y que, en realidad, es una subcategoría de daño instantáneo con efectos consumados en un mismo momento fáctico, a pesar de que éste se prolongue en el tiempo. Así, quedó claro que para que exista un daño continuado debe existir una acción u omisión ilícita repetitiva de manera continua y sin interrupciones que genere un daño que pueda ser reversible. A pesar de la falta de un análisis concreto del tema, se pueden evidenciar vestigios en cierta jurisprudencia como el caso C. con Banco del

${ }^{161}$ El énfasis del texto es la reforma que se plantea para el artículo. 
Pichincha en el que se reclama un daño extrapatrimonial, o el caso S. con la CFN donde se reclama un daño patrimonial.

Respecto a los daños ocultos o tardíos se establecieron dos formas en las que se puede configurar esta tipología. La primera, cuando la totalidad del hecho dañoso se evidencia después de la causa que lo originó, y, la segunda, cuando media entre el hecho generador del daño y el perjuicio, una afectación previa de menor injerencia. Lo importante de esta categoría es conocer que los daños se manifestaran tiempo después del hecho que los originó. En el ordenamiento jurídico ecuatoriano, si han existido indicios de casos con estas características. Se evidencia en los hechos del caso C. B. c. C. y el caso E. c. L., ambos con reclamos por daños extrapatrimoniales.

Así, se esclareció el concepto de daño contingente, donde se evidenció que el artículo 2236 del Código Civil hace referencia a una responsabilidad preventiva. Esta no es una categoría de daño en estricto sentido, dado que la acción busca evitar un daño latente o inminente. El principal requisito para que esta acción prospere es la amenaza de un daño y el justo temor de sufrirlo. Al respecto, esta figura no debería ser estudiada de forma sustantiva por el derecho de daños, toda vez que requiere los mismos requisitos que la justicia cautelar. En este sentido, se evidenció que la apariencia de buen derecho o fumus bonis iuris y el peligro por el retardo o periculum in mora se cumplen si existe el peligro latente de un daño. Respecto de la prescripción, se dejó claro que no es importante en esta figura, por la urgencia e inmediatez que representa. Entonces, se afirma que las acciones del título "De los delitos y cuasidelitos" buscan con ella la indemnización de la afectación, mientras que la acción de daño contingente tiene como objetivo el precaver una afectación.

Como último elemento de análisis, se detallaron los fundamentos y requisitos para que opere la prescripción extintiva en el derecho de daños. Se especificó que, en la responsabilidad extracontractual, la inactividad del afectado debe ser por cuatro años para que opere la prescripción, sin dejar de lado la máxima romana que manifiesta que, si se encuentra imposibilitado el acreedor de actuar, no puede correr en su contra el tiempo establecido por la ley, porque esta solución sería ir en contra de los propósitos mismos de la prescripción y el derecho de daños.

Con esto en mente, se revisaron las distintas soluciones que el derecho comparado tiene para contabilizar la prescripción en daños ocultos y continuados. Se utilizaron normas del derecho español, argentino, chileno, colombiano, alemán y estadounidense, en los que se demuestra que Ecuador requiere una solución que otros países ya han encontrado.

Para finalizar, se evidenció que en Ecuador no es correcto aplicar la interpretación clásica o fundacional del artículo 2235 del Código Civil de manera estricta, porque esta postura olvida que para que exista obligación de indemnizar o reparar los daños sufridos se necesita de los cuatro elementos de la responsabilidad, donde el daño es esencial. A su vez, deja de lado que el derecho de la víctima para reclamar una indemnización civil por vía judicial 
sólo puede prosperar cuando el derecho haya nacido, es decir, cuando se configure un delito o cuasidelito. Por último, la interpretación clásica obvia que si la prescripción opera desde el cometimiento del hecho ilícito en todas los casos, habrá algunos en los que se pierda un derecho que ni siquiera existía; entonces, prescribiría la nada.

Cabe recordar que

"[t]razar la evolución general de la responsabilidad civil permite, a la vez, comprender mejor y medir más exactamente la importancia de la misma[, y] recordar cómo se han modificado, en el transcurso de los siglos las ideas fundamentales que dominan el tema"162.

Esto, trae como consecuencia la necesaria modificación de las concepciones prestablecidas para una correcta aplicación de la prescripción. Sobre la base de una interpretación basada en el espíritu de la norma, literal, lógica y sistemática, se puede precautelar tanto el fundamento de la prescripción, como el derecho de la víctima a ser resarcida. Para ello, la solución factible es realizar una correcta interpretación de los términos "desde la perpetración del acto", en donde la solución dependerá del tipo de daño del que se trate. Es decir, se analizará caso a caso. Para daños continuados o sucesivos se computará desde el último hecho dañoso; para los ocultos, el tiempo correrá desde que la víctima tuvo conocimiento del daño; $y$, para los consumados o inmediatos se contará desde la verificación del hecho ilícito.

En la misma línea, en aras de mayor claridad y seguridad, se propone una reforma del artículo 2235, en la que la regla abarque todos los casos sin excepción y se eviten así discusiones obsoletas fundamentadas en una posición objetiva del artículo in comento, frente a interpretaciones subjetivas actuales y correctas.

\section{BibLiografía CITADA}

Abeliuk, René (2008). Las Obligaciones. Santiago: Editorial Jurídica de Chile, tomo I.

Albiez Dohrmann, Klaus Jochen (2002). "Un nuevo Derecho de obligaciones. La Reforma 2002 del BGB”. Anuario de Derecho Civil, vol. 55, fascículo n. ${ }^{\circ} 3$. Madrid: Ministerios de Justicia - Boletín Oficial del Estado.

Alessandri Rodríguez, Arturo y Manuel Somarriva Undurraga (redactado por Antonio Vodanovic) (1961). Derecho Civil. Parte general. 3 ${ }^{\text {a }}$. Santiago: Ed. Nascimento, tomo I.

Alessandri, Arturo (1991). Derecho Civil parte preliminar y parte general. Santiago: Ediar, tomo II.

${ }^{162}$ Mazeaud et al. (1961), p. 35. 
Alessandri, Arturo (2015). De la Responsabilidad Extracontractual en el Derecho Civil Chileno. Santiago: Editorial Jurídica de Chile.

AlPA, Guido (2006). Nuevo tratado de responsabilidad civil. (trad.) Leysser LEÓN. Lima: Editores Ara.

ArmadÀ, Claudia (2015). "La Talidomida: desde la perspectiva del daño continuado, permanente y tardío". Repositorio Digital Universidad de Girona Facultad de Derecho, 2015-06. Disponible en https://dugi-doc.udg.edu/handle/10256/11823 [Fecha de consulta: 02 de diciembre de 2020].

Bain, Adam y Ugo Colella (2004). "The United States Supreme Court and Federal Law: Interpreting Federal Statutes of Limitations". Creighton Law Review, vol. 37. Omaha: Creighton University.

Barbero, Doménico (1967). Sistema del Derecho Privado. Buenos Aires: ed. Jurídicas Europa-América, tomo I.

Barros, Enrique (2006). Tratado de Responsabilidad Extracontractual. Santiago: Editorial Jurídica de Chile.

BeLLo, Andrés (1887a). "Proyecto de Código Civil 1841 - 1845", en Andrés BeLLo. Obras Completas de Don Andrés Bello, vol. XI. Santiago: Consejo de Instrucción Pública.

Bello, Andrés (1887b). "Proyecto de Código Civil 1847”, en Andrés Bello. Obras Completas de Don Andrés Bello, vol. xI. Santiago: Consejo de Instrucción Pública.

Bello, Andrés (1887c). "Proyecto de Código Civil 1853", en Andrés Bello. Obras Completas de Don Andrés Bello, vol. XI. Santiago: Consejo de Instrucción Pública.

Borda, Guillermo (2008). Tratado de Derecho Civil. $9^{\text {a }}$ edición. Buenos Aires: La Ley, tomo II, obligaciones.

Busnelli, Francesco D. (1984). Il diritto civile tra codice e legislazione speciale. Napoli: Guida.

Bustamante Alsina, Jorge (1998). Teoría General de la Responsabilidad Civil. $9^{\mathrm{a}}$ edición. Buenos Aires: Abeledo-Perrot.

Calamandrei, Piero (1945). Introducción al estudio sistemático de las providencias cautelares. (trad.) S. SANTis. Buenos Aires: Bibliografía Argentina.

Cavanillas, Santiago (2013). "Artículo 1968", en Rodrigo Bercovitz RodriguezCAno (dir.). Comentarios al Código Civil, prescripción extintiva. Valencia: Tirant lo Blanch, tomo IX.

Chinchilla, Carmen (1993). "El derecho a la tutela cautelar como garantía de la efectividad de las resoluciones judiciales". Revista de Administración Pública, n. ${ }^{\circ}$ 131. Madrid: Centro de Estudios Políticos y Constitucionales

Claro Solar, Luis (1978). Explicaciones de Derecho Civil Chileno y Comparado. Santiago de Chile: Editorial Jurídica de Chile

Colin, Ambrosio y Henri CAPITANT (1939). Cours élémentaire de droit civil francais. Paris: Librairie Dalloz, tomo I.

Coronel, Leonardo y Anabela Chiriboga (2019). "La excepción a la cosa juzgada en materia penal cuando se trata de indemnizaciones civiles". USFQ Law Reviere, vol. vI. Quito: USFQ PRESS. 
Corral, Hernán (2003). Lecciones de Responsabilidad Civil Extracontractual. Santiago: Editorial Jurídica de Chile.

De Cupis, Adriano (1975). El daño. Teoría general de la responsabilidad civil. (trad.) Ángel Martínez. Barcelona: Editorial Bosch.

De Lorenzo, Miguel (1996). El daño injusto en la responsabilidad civil, Alterum Non Laedere. Buenos Aires: Abeledo-Perrot.

Devis Echandía, Hernando (2017). Teoría General del Proceso. $2^{a}$ edición. Bogotá: Editorial Temis.

Diccionario de la Real Academia Española (2020).

Diccionario del español Jurídico de la Real Academia de la Lengua Española (2020).

Diez Schwerter, José Luis y Verónica Delgado Schneider (2003). "Algunas útiles herramientas olvidadas en nuestra práctica del 'Derecho de Daños"'. Revista de Derecho Universidad de Concepción, n. ${ }^{\circ}$ 214, Concepción.

Diez Schwerter, José Luis (2016b). "La aplicación de la acción por daño contingente en Chile, Colombia y Ecuador: del modelo de Bello a nuestros días". Revista de Derecho Privado, Universidad Externado de Colombia, n. 30, Bogotá.

Díez Schwerter, José Luis (2016a). "La acción de daño contingente del artículo 2333 del Código Civil chileno: sus elementos y ámbito de aplicación”. Revista de Derecho de la Pontificia Universidad Católica de Valparaíso, Xlvi, Valparaíso.

266 Diez-Picazo, Luis (2005). Fundamentos del Derecho Civil Patrimonial. Madrid: Civitas, vol. III.

Domínguez Águila, Ramón (2020a). La prescripción extintiva. Doctrina y Jurisprudencia. Santiago: Prolibros.

Domínguez Águila, Ramón (2020b). "Inicio de la prescripción en caso de cuasidelito civil”. Revista de Derecho Universidad de Concepción, 88, 247, Concepción.

Echevesti, Carlos (1997). "Las acciones por daños y perjuicios”, en Jorge Mosset Iturraspe (dir.). Responsabilidad Civil. Buenos Aires: Hammurabi.

EsCudero, Hernán (2019). "La vigencia del principio alterum non laedere y la inexistencia de la antijuridicidad como presupuesto material de la responsabilidad civil”. Repositorio Digital USFQ Colegio de Jurisprudencia, n. ${ }^{\circ}$ 19. Disponible en https://repositorio.usfq.edu.ec/jspui/handle/23000/8934 [Fecha de consulta: 02 de diciembre de 2020].

FERRADA, Luis (2012). "La interpretatio per aliam legem como regla para definir el sentido del artículo 2232 del código civil, sobre prescripción de la acción de responsabilidad extracontractual". Revista de Derecho Escuela de Postgrado n. ${ }^{\circ}$ 2, Universidad de Chile, Santiago.

Green, Michael (1988). "The Paradox of Statutes of Limitations in Toxic Substances Litigation". California Law Review, vol. 76, n. ${ }^{\circ}$, California.

Henao, Juan Carlos (1998). El daño, análisis comparativo de la responsabilidad extracontractual del Estado en el derecho colombiano y francés. Bogotá: Universidad Externado de Colombia. 
JAKSIC, Ivan (2003). "La cultura y el problema del orden en la América Andina 1830 - 1880: la labor de Andrés Bello”, en Juan Maiguashca (edit.). Historia de América Andina. Quito: Universidad Andina Simón Bolívar - Libresa.

López Herrera, Edgardo (2007). Tratado de la prescripción liberatoria. Buenos Aires: LexisNexis.

Marín López, Manuel (2014). "El cómputo del tiempo en la prescripción extintiva. En particular, el dies a quo del plazo de prescripción”, en Manuel MARín López et al. La Prescripción Extintiva, XVII Jornadas de la Asociación de profesores de Derecho Civil. Valencia: Tirant lo Blanch.

Mazeaud, Henri et al. (1961). Tratado Teórico Práctico de la Responsabilidad Civil Delictual y Cuasidelictual. $5^{\text {a }}$ edición. Buenos Aires: Ediciones Jurídicas EuropaAmérica.

Moisset de Espanés, Luis (1968). Interrupción de la Prescripción por Demanda. Córdoba: Imprenta de la Universidad Nacional de Córdoba.

Moisset de Espanés, Luis (1987). "Prescripción”. Colegio de Escribanos de Córdoba Revista Notarial, n. ${ }^{\circ}$ 54. Córdoba: Colegio de Escribanos.

Moisset de Espanés, Luis (1990). "La reparación de los daños continuados o permanentes". Academia Nacional de Derecho y Ciencias Sociales de Córdoba. Córdoba: ACADERC.

Moisset de Espanés, Luis (2004). Prescripción. Córdoba: Advocatus.

Narula, Ritu (2010). "Wait, I Didn't Even Know My Picture Was Taken!: Application of the Discovery Rule to a Right of Publicity Claim". Howard Law Journal. vol. 53, Notre Dame.

Ospina Fernández, Guillermo (2018). Régimen General de las Obligaciones. $5^{\mathrm{a}}$ Edición. Bogotá: Temis.

Parraguez, Luis (2000a). Manual de Derecho Civil Ecuatoriano Libro Cuarto Teoría General de las Obligaciones. Loja: Universidad Técnica Particular de Loja, vol. I.

Parraguez, Luis (2000b). Anexo de apuntes de Código Civil, libro cuarto; Teoría General de las Obligaciones. Loja: Universidad Técnica Partículas de Loja.

Parraguez, Luis (2016). El Régimen Jurídico de los Bienes. Quito: Ediciones IURIS DICTIO Colegio de Jurisprudencia Universidad San Francisco de Quito.

Peña López, Fernando (2012). "El dies a quo y el plazo de prescripción de las acciones de responsabilidad por daños en el CC: criterios procedentes de algunos textos europeos de soft law y del Derecho estadounidense que podrían servir para su reforma e interpretación”. InDret Revista para el Análisis del Derecho, n. ${ }^{\circ}$ 1, Universitat Pompeu Fabra, Barcelona.

Pothier, Robert (2008). Tratado de las Obligaciones. $3^{\text {a }}$ edición. Barcelona: Biblioteca Científica y Literaria.

Reglero Campos, Luis (2008). "La prescripción de la acción de reclamación de daños”, en Luis Reglero Campos (coord.). Tratado de Responsabilidad Civil. Cizur Menor: Thomson Aranzadi, tomo I. 
Roca, Encarna y Mónica Navarro (2016). Derecho de Daños, Textos y materiales. $7^{\mathrm{a}}$ edición. Valencia: Tirant lo Blanch.

Tamayo Jaramillo, Javier (2007). Tratado de Responsabilidad Civil. Bogotá: Legis Editores, tomo II.

TAPIA, Orlando (2016). De la Responsabilidad civil en general y de la responsabilidad delictual entre los contratantes. Concepción: Publicaciones del Seminario de derecho privado de la Facultad de Cs. Jurídicas y Sociales, Escuela tipográfica salesiana.

Torralba, Pablo (2014). "Daños Permanentes, Continuados y Sobrevenidos". Repositorio Digital Universidad Pública de Navarra Facultad de Ciencias Jurídicas, n. ${ }^{\circ} 14$. Disponible en https://academica-e.unavarra.es/xmlui/handle/2454/11264 [Fecha de consulta: 02 de diciembre de 2020].

Velásquez Posada, Obdulio (2016). Responsabilidad Civil Extracontractual. $2^{\mathrm{a}}$ edición. Bogotá: Editorial Temis.

Vergara, José Pablo (2004). "Momento inicial del cómputo de la prescripción extintiva de la responsabilidad extracontractual". Revista de Derecho Consejo de Defensa del Estado, ${ }^{\circ} 12$, Santiago.

Vergara, José Pablo (2011). “Aceptación jurisprudencial de la doctrina de que la prescripción extintiva de que la responsabilidad extracontractual empieza a correr desde la perpetración del acto ilícito y no a contar de la producción del daño", en Hernán Corral (ed.). Prescripción extintiva. Estudios sobre su procedencia y funcionamiento en Derecho Público y Privado. Cuadernos de Extensión Jurídica, Universidad de los Andes, Santiago, n. ${ }^{\circ} 21$.

Vodanovic, Antonio (2001). Manual de Derecho Civil. Santiago: Ed. Conosur Ltda., II volumen de las partes preliminar y general.

Von IHERING, Rudolf (1880). Études complementaires de l'espirit de droit romain. París: De la Faute en droit privé.

WACKE, Andreas (2013). "La reformas más importantes del BGB desde su promulgacíno en 1900, con especial referencia al Derecho de obligaciones". Revista Chilena de Derecho, vol. 40, n. ${ }^{\circ}$, Santiago.

Weingarten, Celia (2005). Responsabilidad por prestaciones odontológicas. Buenos Aires: Astrea.

YzQuierdo Tolsada, Mariano (1993). Responsabilidad Civil Contractual y extracontractual. Madrid: Reus.

Zannoni, Eduardo (2005). El daño en la responsabilidad civil. $3^{\text {a }}$ edición. Buenos Aires: Astrea.

\section{Normas citadas}

Código Civil español. BOE-A-1889-4763, de 25 de julio de 1889.

Código Civil. Registro Oficial, suplemento 46, 24 de junio de 2005, reformado por última vez el 08 de julio de 2019. 
Código Orgánico Integral Penal. Registro Oficial, suplemento 180, 10 de febrero de 2014, reformado por última vez el 04 de diciembre de 2019.

Constitución de la República del Ecuador, Registro Oficial $\mathrm{N}^{\circ}$ 449, 20 de octubre del 2008, reformado por última vez el 12 de marzo del 2020.

Ley n. ${ }^{\circ} 171$ [reformatoria del Código Civil sobre Reparación de Daños Morales], Registro Oficial 779, 04 de julio de 1984.

Ley n. ${ }^{\circ} 18525$ [Código Civilchileno], Diario Oficialde la Nación, de 30 de junio de 1986. Ley n. ${ }^{\circ} 42$ de 1998, Diario Oficial No. 43.357, 06 de agosto de 1998.

Ley n. ${ }^{\circ} 57$ de 1887 [Código Civil Colombiano], Diario Oficial n. ${ }^{\circ}$ 2867, 26 de mayo de 1873.

Ley n. ${ }^{\circ} 26.994$ [Código Civil argentino], Boletín Oficial de la República Argentina, 08 de octubre de 2014 .

\section{Jurisprudencia citada}

A. y otros con Chevron Corporation (2012): Corte Provincial de Sucumbíos, sala única, 09 de enero de 2012, causa n. ${ }^{\circ}$ 2011-0106, en Plataforma Digital e-satje, p. 6.

Caso n. ${ }^{\circ}$ 17042-3103-001-2005-00103-01 (2010): Corte Suprema de Justicia de Colombia, sala de casación civil, 09 de septiembre de 2010, en Actualícese. Disponible en https://actualicese.com/sentencia-17042-3103-001-2005-0010301-de-09-09-2010/ [Fecha de consulta: 02 de diciembre de 2020].

Caso n. ${ }^{\circ}$ SC016-2018 (2018): Corte Suprema de Colombia, sala de casación civil, 24 de enero de 2018, pp. 16-20.

Causa n. ${ }^{\circ}$ 1255/2008 (2007): Tribunal Supremo de España, sala de lo civil, 20 de noviembre de 2007 en Registro Judicial 1255/2008, p. 12.

Causa n..$^{\circ}$ 170/20005 (2009): Tribunal Supremo de España, sala civil, 28 de octubre de 2009 en Registro Judicial 2009/170, pp. 3-4.

Causa n. ${ }^{\circ}$ 1580/2014 (2016): Tribunal Supremo de España, sala de lo civil, 04 de julio de 2016 en Registro Judicial 2016/1580, p. 4.

Causa n. ${ }^{\circ}$ 170/2005 (2009): Tribunal Supremo de España, sala civil, 28 de octubre de 2009, en Registro Judicial 2009/170, pp. 2-4.

Causa n. ${ }^{\circ} 2509 / 2011$ (2014): Tribunal Supremo de España, sala de lo civil, 29 de enero de 2014, en Registro Judicial 2014/2509, p. 4.

Causa n. ${ }^{\circ}$ 28/2014 (2014): Tribunal Supremo de España, sala de lo civil, 29 de enero de 2014 en Registro Judicial 2014/796.

Causa n. ${ }^{4} 431 / 2000$ (2007): Tribunal Supremo de España, sala de lo civil, 23 de noviembre de 2007, en Registro Judicial 2007/4331, pp. 2-4

C. con Constructora S. (1983): Corte Suprema de Justicia del Ecuador, primera sala de lo civil y mercantil, 21 de enero de 1983 en Gaceta Judicial, año LXXXIII, serie XIV, 2, p. 399. 
Comité D. T. viuda de C. con Petroecuador (2002): Corte Suprema de Justicia del Ecuador, primera sala de lo civil y mercantil, 29 de octubre de 2002, en Gaceta Judicial, serie XVII n. ${ }^{\circ}$ 10, p. 301.

Constructora B. con Banco Central de la República Argentina (1997): Corte Suprema de Argentina, fallo 312:2352, 15 de junio de 1997 en SAIJ de Argentina. Disponible en http://www.saij.gob.ar/camara-nac-apelaciones-civil-comercialfederal-federal-ciudad-autonoma-buenos-aires-constructora-barcala-sa-bancocentral-republica-argentina-ordinario-fa89030101-1989-03-17/123456789101-0309-8ots-eupmocsollaf? [Fecha de consulta: 02 de diciembre de 2020].

C. con Banco Pichincha (2012): Corte Nacional de Justicia, sala de lo civil y mercantil, 13 de septiembre de 2012, caso n. ${ }^{\circ}$ 946-2009-SR, en Registro Oficial, edición especial n. ${ }^{\circ} 330$, año IV.

C. y B. con Conclina C.A. (2004): Juzgado Quinto de lo Civil, 17 de diciembre de 2004, caso n. ${ }^{\circ}$ 2002-0078, en Plataforma Digital e-satje.

E. con L. (2018): Corte Provincial de Pichincha, sala de lo civil y mercantil, 06 de junio de 2018, caso n. ${ }^{\circ}$ 2014-990, en Plataforma Digital e-satje.

E. con L. (2019): Corte Nacional de Justicia, sala de lo civil y mercantil, 13 de noviembre 2019, caso n. ${ }^{\circ}$ 2014-990, en Plataforma Digital e-satje.

E. con Fisco de Chile (2018): Corte Suprema de Chile, tercera sala de casación, 19 de abril de 2018, en westlawchile.cl, p. 12.

270 G. R. con Río Negro (2010): Corte Suprema de Argentina, fallo 340:1982, 01 de junio de 2010, en SAIJ de Argentina.

M.L. con AECA (2004): Corte Suprema de Justicia, primera sala de lo civil y mercantil, 05 de febrero de 2004, caso n. ${ }^{\circ}$ 290-2003, en Lexis, p. 6.

M.R. con Salud del Biobío (2020), rol n. ${ }^{\circ}$ 23145-2019, en Poder Judicial: www.pjud.cl.

RDJ, t. LXXVIII, sec. 5ta (1981): Corte Suprema de Chile, 06 de noviembre de 1981, pág. 29 (citado por Corral Talciani [2003], p. 350).

S. M. E. S y Cía. S.C.A. con Provincia de Buenos Aires (2002): Corte Suprema de Argentina, J.A. 2003-II-289, 05 de noviembre de 2002, en SAIJ de Argentina.

S. con CFN (2011): Corte Provincial del Guayas, sala de lo civil y mercantil, 07 de noviembre del 2011, causa n. ${ }^{\circ}$ 2010-0374, p. 7, en Plataforma Digital e-satje.

D.T con Estado Nacional (1999): Corte Suprema de Argentina, J.A. 2000-III-680, 31 de agosto de 1999, en SAIJ de Argentina.

T. y otros con S. (2019): Cámara de Apelaciones en lo Civil y Comercial, sala segunda, 09 de abril de 2019, en SAIJ de Argentina.

U. con T. (1947): Tribunal Supremo de los Estados Unidos, excepción a la Statue of Limitation, 31 de mayo de 1947, caso 337 US 163, en Justitia US Supreme Court.

V. con Colegio de Médicos de Imbabura (2003): Corte Suprema de Justicia del Ecuador, primera sala de lo civil y mercantil, 02 de abril del 2003, causa n. ${ }^{\circ} 43-$ 2002 en Gaceta Judicial, año CIV, serie XVII, n. ${ }^{\circ}$ 12, p. 3734. 
SiglaS Y ABREVIATURAS

Código Civil Código Civil ecuatoriano de Registro Oficial, suplemento 46, 24 de junio de 2005, reformado por última vez el 08 de julio de 2019.

RAE Real Academia de la Lengua Española. Código Civil chileno Ley n. ${ }^{\circ} 18525$ de Diario Oficial de la Nación, de 30 de junio de 1986.

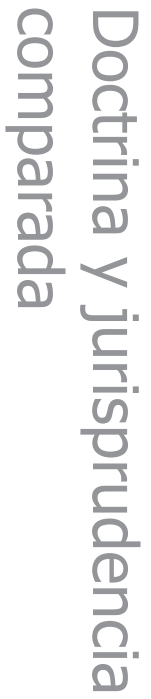

